\title{
Influence of Orientation and Arrangement of Structures on Tsunami Impact Forces: Numerical Investigation with Smoothed Particle Hydrodynamics
}

DOI:

10.1061/(ASCE)WW.1943-5460.0000629

\section{Document Version}

Accepted author manuscript

Link to publication record in Manchester Research Explorer

Citation for published version (APA):

Pringgana, G., Cunningham, L., \& Rogers, B. D. (2021). Influence of Orientation and Arrangement of Structures on Tsunami Impact Forces: Numerical Investigation with Smoothed Particle Hydrodynamics. Journal of Waterway, Port, Coastal and Ocean Engineering, 147(3). https://doi.org/10.1061/(ASCE)WW.1943-5460.0000629

Published in:

Journal of Waterway, Port, Coastal and Ocean Engineering

\section{Citing this paper}

Please note that where the full-text provided on Manchester Research Explorer is the Author Accepted Manuscript or Proof version this may differ from the final Published version. If citing, it is advised that you check and use the publisher's definitive version.

\section{General rights}

Copyright and moral rights for the publications made accessible in the Research Explorer are retained by the authors and/or other copyright owners and it is a condition of accessing publications that users recognise and abide by the legal requirements associated with these rights.

\section{Takedown policy}

If you believe that this document breaches copyright please refer to the University of Manchester's Takedown Procedures [http://man.ac.uk/04Y6Bo] or contact uml.scholarlycommunications@manchester.ac.uk providing relevant details, so we can investigate your claim.

\section{OPEN ACCESS}




\section{Influence of Orientation and Arrangement of Structures on Tsunami Impact Forces: a numerical investigation with Smoothed Particle Hydrodynamics}

Gede Pringgana, PhD, AMASCE${ }^{1}$; Lee S. Cunningham, MEng, PhD, CEng, MICE, MIStructE, MASCE, FHEA ${ }^{2}$; Benedict D. Rogers, MEng, DPhil (Oxon), FHEA ${ }^{3}$

${ }^{1}$ Lecturer, Civil Engineering Study Program, Faculty of Engineering, Udayana University,

6 Kampus Bukit Jimbaran 80361, Bali, Indonesia. E-mail: gedepringgana @ unud.ac.id.

${ }^{2}$ Senior Lecturer in Civil Engineering, Department of Mechanical, Aerospace and Civil Engineering, The University of Manchester, Manchester M13 9PL, UK. E-mail:

9 lee.scott.cunningham@manchester.ac.uk.

$10{ }^{3}$ Professor of Fluid Mechanics and Chair of Computational Hydraulics, Department of

11 Mechanical, Aerospace and Civil Engineering, The University of Manchester, Manchester

12 M13 9PL, UK. E-mail: benedict.rogers@manchester.ac.uk.

13 Corresponding Author: gedepringgana@unud.ac.id

\section{Abstract}

This paper explores the influence of onshore structures' orientations and arrangements during tsunami impact using the numerical method of smoothed particle hydrodynamics (SPH). Observations from previous tsunami events often reveal variation in the damage and survivability of impacted similar structures. Such variation can be due to shielding effects and other interactions that occur when the tsunami wave is incident upon an urbanised location. The SPH model used in this work was first validated against previous experimental results and was then used to explore the resulting hydrodynamic behaviour to a level of detail hitherto unobtainable from physical experiments. Groups of three and five structures were modelled with varying spatial separation and orientation to the incoming tsunami bore, characterised by the wake clearance angle (A) and the rotation angle (R), respectively. The results reveal significant reductions in total force on a structure can be made via strategic spatial positioning and orientation. Such reductions may mean the difference between superficial damage and wholesale structural collapse and allow the development of more resilient structures in tsunami-prone regions.

Keywords: tsunami, force, macro-roughness, orientation, arrangement, SPH.

\section{Introduction}

The impact of earthquake-induced tsunamis on coastal communities are enormous in both human and socio-economic costs (Suppasri et al. 2015; Imamura et al. 2019). Earthquake induced tsunamis are a potential threat to countries located at the tectonic plate junctions 
(Murty et al. 2006). The devastating effects of the 2004 Indian Ocean tsunami on onshore infrastructure were widely observed (Saatcioglu et al. 2005; Levy and Gopalakrishnan 2005; Ghobarah et al. 2006; Morin et al. 2008; Leone et al. 2011). The 2004 Indian Ocean tsunami, identified as the first global-scale tsunami to occur during the "instrumental era" (Rabinovich et al. 2006), caused various extents of structural damage across many countries (Lau et al. 2015). Similarly, the 2011 Tohoku-Japan tsunami caused more than 400,000 structures to be damaged or destroyed (Mikami et al. 2012; Suppasri et al. 2012; Suppasri et al. 2013; Chock et al. 2013). More recently, in 2018, the Palu-Indonesia tsunami and its subsequent widespread liquefaction caused severe damage to infrastructure, killing 2096 people with 1373 people reported as missing (Syamsidik et al. 2019). In the same year, a volcanic-induced tsunami in Indonesia which was triggered by the Mount Anak Krakatau eruption also damaged a significant amount of structures, killed 437 people and injured more than 30,000 (Syamsidik et al. 2020).

Learning from past events, a full recovery following tsunami disasters can take years or even decades (Leelawat et al. 2015). For more resilient communities, infrastructure needs to remain functional and become functional immediately after the disaster (ASCE/SEI 2017; Macabuag et al. 2018). To prevent infrastructure damage caused by tsunami, mitigation strategies have been investigated both experimentally and numerically, including natural protection by mangroves (Alongi 2008) and traditional coastal defences (Kihara et al. 2015). Recent developments in the design of tsunami-resistant onshore structures have heightened the need to improve the capacity of building structures including strength, stiffness and ductility to overcome earthquakes and tsunamis sequentially (Rossetto et al. 2019; Petrone et al. 2020) and also to reduce the hydrodynamic impact forces exerted on the surface of structures. It has been observed that elevated structures and the presence of break-away walls and openings could be effective strategies to reduce wave-induced pressures (Thusyanthan and Madabhushi 2008; Wilson et al. 2009; Lukkunaprasit et al. 2009; FEMA 2011; Triatmadja and Nurhasanah 2012; Chinnarasri et al. 2013; Hartana and Murakami 2015; Ghosh et al. 2016; Park et al. 2017; Tomiczek et al. 2019).

In light of recent tsunami events, it is becoming difficult to ignore the complex interactions of tsunami flows with nearby buildings (often termed macro-roughness elements). Video evidence reviewed by Robertson et al. (2013) comprising footage of tsunami inundation in Onagawa during the 2011 Japan tsunami, reveals the tsunami incoming flow channelling between and around buildings. In the video, flow focusing occurred between two adjacent 
surviving buildings that provided shielding to buildings behind them. The flow focusing effect caused overturning of concrete and steel buildings and severe damage to a steel framed shopping centre at the end of the channel. For the case of vernacular structures, a post-tsunami survey of buildings in Sri Lanka following the 2004 tsunami revealed the importance of building orientation on survivability and damage levels (Dias and Mallikarachchi 2006). The aforementioned studies and evidence from elsewhere suggest that spatial distribution and orientation play important roles for the resilience of onshore structures subject to tsunami events.

To date, there has been a relatively limited amount of studies investigating the 76 hydrodynamics of tsunami inundation of multiple structures or macro-roughness elements. Cox et al. (2008) presented a 1:50 physical model of the town of Seaside, Oregon, USA, to develop data sets for the evaluation of the numerical tool COULWAVE based on a depth-integrated formulation. This offered accurate estimations for a wide range of nearshore wave evolution, including shoaling, breaking and run-up. This topic was continued by Park et al. (2013), focusing on the observation of free surface elevation, velocity and momentum flux. Park et al. (2013) underlined the importance of performing the velocity comparison in the validation and verification process of numerical modelling using COULWAVE and considered the bottom friction parameter in terms of the friction factor which was found highly sensitive to the model's velocity and momentum flux. Goseberg and Schlurmann (2012) and Goseberg (2013) conducted physical experiments that showed the effectiveness of 45-degree rotated and unrotated macro-roughness elements to reduce tsunami run-up on a sloping beach and produced nomograms to predict the maximum wave run-up. Thomas et al. (2015) presented experimental data on the effect of macro-roughness on tsunami flow in the inundation zone and the influence of the wake clearance angle on the resulting loads. The wake clearance angle was defined by Thomas et al. (2015) as "the angle between (1) the line passing through the centre of the specimen perpendicular to the breaking wave and (2) the line created by connecting the front centre of the specimen to the leading inside corner of the macro-roughness element". Tomiczek et al. (2016) performed physical modelling considering the tsunami onshore propagation and the effect of shielding by an array of structures that could reduce the wave-induced forces. The research was extended by Tomiczek et al. (2017), where the experimental resulting forces were compared with the US and Japanese design equations. The comparison showed that generally the design codes' total force estimations over and under-estimated the test results for non- 
seaward (front) and leeward (rear) face pressures on macro-roughness elements caused by nonovertopping and overtopping wave flows. The physical testing outcomes indicated that the seaward macro-roughness significantly influenced the front and back face pressures.

The majority of previous research regarding macro-roughness elements was based on laboratory experiments. Whilst physical modelling is important, the obtained data is limited by practical constraints such the degree of instrumentation and size of laboratory facilities. Use of numerical modelling allows detailed capture of all the key hydrodynamic data throughout the time and spatial domain of the simulation. Some numerical models previously developed to study the interactions between tsunami and macro-roughness elements include the Storm Surge and Tsunami Simulator in Oceans and Coastal Areas, STOC (Tomita et al. 2004) and the Cornell University Long and Intermediate Wave Modeling Package, COULWAVE (Lynett et al. 2002; Cox et al. 2008; Park et al. 2013). Recently, Qin et al. (2018) modelled tsunami inundation on an urban area with a multi-phase air-water model using the software OpenFOAM. The results revealed good agreement with experimental data, while the computational time of the simulation was reported as 9-10 days using parallel processing. STOC, COULWAVE and OpenFOAM are mesh-based numerical models that utilise computational grids. In a different way, the numerical modelling in this study uses the meshless smoothed particle hydrodynamics (SPH) method using the validated open-source software DualSPHysics (Gomez-Gesteira et al. 2012a, 2012b; Crespo et al. 2015). Thanks to its meshless formulation, SPH offers distinct advantages to simulate highly violent bore and tsunami-structure interaction and was therefore employed due to its proven capability in wave breaking applications (Altomare et al. 2015; Baines et al. 2019). Previously, the SPH method has also been successfully utilised to investigate the interaction between tsunami-like waves and an isolated single structure (Cunningham et al. 2014; St-Germain et al. 2014; Pringgana et al. 2016). Using the experimental work of Thomas et al. (2015) as a base, the present work numerically explores the phenomenon of tsunami inundation of multiple buildings and extends the original experimental work to consider a wider variation of spatial distributions and orientations. In using a numerical approach, the pressure distribution and force estimation on every single macro-roughness element and the prediction of pressure distribution across the surface of the structures is captured. This present study attempts to show that the optimum orientation of structures can significantly reduce the hydrodynamic impact forces on a structure's vertical surfaces in parallel with the effect the spatial distribution of multiple structures. 
This paper is structured as follows. The Methodology section presents the SPH

134 background theory and force calculation employed for this study. This is then followed by a validation study based on the experiments of Thomas et al. (2015) and the subsequent numerical extension of this to include a greater suite of geometric parameters. The outcomes of the extended numerical work are presented in the Results section. The closing two sections discuss the limitations and implications of the study and present the key conclusions.

\section{Smoothed Particle Hydrodynamics (SPH) Background Theory}

SPH is a meshless Lagrangian technique that has been shown to be effective in solving diverse fluid-dynamics problems with highly nonlinear deformation such as tsunami inundation, wave breaking and impact and fluid-structure interaction (Barreiro et al. 2013). The SPH particles can be considered as material points that have extensive quantities (i.e. mass, volume) and intensive quantities (i.e. velocity, pressure, density, specific internal energy, turbulent kinetic energy), as stated by Violeau and Rogers (2016). The quantities of the SPH particles are interpolated based on their positions that follow trajectories during their motions. The discrete interpolation uses a summation of contributions from surrounding neighbouring particles using a weighting function (kernel) since there is no computational mesh involved. The properties of the SPH particle is therfore influenced by its neighbouring particle inside the compact support of the kernel which has a characteristic length called the smoothing length $h$, as can be seen in Fig.1.

The quantity value of an SPH particle $A(\boldsymbol{r})$ located at position $\boldsymbol{r}$, can be approximated by an integral interpolant (Gomez-Gesteira et al. 2012b):

$$
\langle A(\boldsymbol{r})\rangle=\int_{\Omega} A\left(\boldsymbol{r}^{\prime}\right) W\left(\boldsymbol{r}-\boldsymbol{r}^{\prime}, h\right) d \boldsymbol{r}^{\prime}
$$

where $W\left(\boldsymbol{r}-\boldsymbol{r}^{\prime}, h\right)$ is the weighting function or kernel, $h$ is the smoothing length that controls the radius of influence of domain $\Omega$ and $\langle\ldots\rangle$ denotes an approximation. In discrete notation, can be expressed in the following approximation at interpolant point $a$,

$$
A\left(\boldsymbol{r}_{a}\right)=\sum_{b} A_{b} \frac{m_{b}}{\rho_{b}} W_{a b}
$$
where the subscript refers to each particle, $m$ is the mass, $\rho$ is density and $W_{a b}=$ $W\left(\boldsymbol{r}_{a}-\boldsymbol{r}_{b}, h\right)$. The summation is performed over all particles $b$ inside the region of compact support of the kernel function, as shown by Fig. 1. The kernel functions possess several 
properties (Monaghan 1992) such as positivity within the area of interaction, compact support, normalization and monotonic decrease with distance (Altomare et al. 2015). The performance of an SPH model is strongly influenced by the selection of the smoothing kernel used in the model (Crespo et al. 2015). A fifth-order Wendland kernel is used in all models presented in this paper (Wendland 1995).

In this work, the weakly compressible SPH formulation is used to approximate the fluid.

167 The weakly compressible SPH model solves the conservation of mass and momentum in 168 Lagrangian form as

$$
\begin{gathered}
\frac{d \rho}{d t}=-\rho \nabla \cdot \boldsymbol{v} \\
\frac{d \boldsymbol{v}}{d t}=-\frac{1}{\rho} \nabla P+\boldsymbol{g}+\Gamma
\end{gathered}
$$

169

170

171

172

173

174

175

176

177

178

where $\boldsymbol{v}$ is the velocity, $t$ is the time, $\rho$ is the density, $P$ is the pressure, $\boldsymbol{g}$ is the gravitational acceleration and $\Gamma$ is the dissipative term. In relation to the changes of fluid particle density, the continuity equation, Eq. 3, can be expressed in the following SPH form:

$$
\frac{d \rho_{a}}{d t}=\sum_{b} m_{b} \boldsymbol{v}_{a b} \cdot \nabla_{a} \boldsymbol{W}_{a b}+\delta^{S P H}
$$

where $\boldsymbol{v}_{a b}=\boldsymbol{v}_{a}-\boldsymbol{v}_{b}$ and $\nabla_{a} \boldsymbol{W}_{a b}$ denotes the derivative of the smoothing kernel $\boldsymbol{W}_{a b}$ with respect to the coordinates of particle $a$ and $\delta^{S P H}$ is the delta-SPH correction explained below. To conserve the momentum as shown by Eq. 4, the pressure gradient in SPH notation uses a symetric form of gradient as follows:

$$
\frac{d \boldsymbol{v}_{a}}{d t}=-\sum_{b} m_{b}\left(\frac{P_{a}}{\rho_{a}^{2}}+\frac{P_{b}}{\rho_{b}^{2}}+\Pi_{a b}\right) \cdot \nabla_{a} \boldsymbol{W}_{a b}+\boldsymbol{g}
$$

where $\Pi_{a b}$ represents viscous forces. In weakly compressible SPH, the density fluctuation inherent in the method can be reduced by applying a delta-SPH formulation (Antuono et al. 2015; Marrone et al. 2011). A delta-SPH coefficient of 0.1 is suggested for general applications. For a full description of the SPH formulation used, readers are referred to Crespo et al. (2015). Eq. 3 and Eq. 4 are closed by using an equation of state relating pressure to density. In weakly compressible SPH the equation of state commonly used is

$$
P=B\left[\left(\frac{\rho}{\rho_{0}}\right)^{\gamma}-1\right]
$$

where $\gamma=7$ for water recommended by Monaghan (1994) which proved to be efficient, $\rho_{0}=$ $1000 \mathrm{~kg} \mathrm{~m}^{-3}$ is the reference density, $B=c_{0}^{2} \rho_{0} / \gamma$, and the speed of sound at the reference density is denoted by $c_{o}=c\left(\rho_{o}\right)=\left.\sqrt{(\partial P / \partial \rho)}\right|_{\rho_{o}}$. The maximum relative density fluctuations 
scale with the Mach number squared $O\left(\mathrm{M}^{2}\right)$ as shown by an analysis of the compressible Navier-Stokes equations (Monaghan 1994). Using the real speed of sound leads to prohibitively small timestesps in the simulation. Hence, to enable timesteps sufficiently large for simulations, the numerical speed of sound is adjusted to be at least ten times faster than the maximum fluid velocity where this restriction limits the density variation to within less than $\mathrm{M}^{2}=0.01$ or $1 \%$, keeping the particle spacing approximately constant, and prevents major deviation from incompressible behaviour.

\section{Measurement of Numerical Pressures and Calculation of Forces}

In the numerical water tank, the set up of the wave-maker and structures inside the water tank, the wave and bore simulations will be performed in 3-D, thus the entire system is based on three main axes: $x, y$ and $z$ as global directions. The water surface elevation has value only in the $z$-direction, while the velocity has values in the $x, y$ and $z$-directions. The impacttargeted structure in the numerical model is idealised in the form of a cube with four vertical surfaces where the tsunami-induced forces may be acting, this also follows the approach adopted in the physical model undertaken by Thomas et al (2015). As illustrated in Fig. 2, following Pringgana et al. (2016), the pressure distribution on the face of a structure is obtained from numerical pressure probes distributed regularly over the face. The force is then obtained by summing the pressure multipled by the area that is impacted by the tsunami bore, following Eq. 8 and Eq. 9. In all simulations presented herein, the force considered is, unless noted otherwise, the resultant acting on the structure in the direction of tsunami approach. For some of the rotated structure cases, the force resultant perpendicular to tsunami approach is also examined. The tsunami wave is generated and propagated along the water tank in the $x$ direction, hence the total resolved forces of interest are $F_{\text {total }}^{x}$ and $F_{\text {total }}^{y}$ in the $x$ and $y$-direction. As shown in Fig. 3(a), for the case where the unrotated structure's surface is perpendicular to the direction of the oncoming tsunami wave, the acting force, $F$, gives $F_{\text {total }}^{x}$ directly since for this case only one side of the structure will be impacted by the bore flow. If the structure is rotated clockwise by an angle $\theta$, as illustrated in Fig. 3(b), two sides of the surface are assumed to be impacted by the tsunami bore. The normal forces, which are perpendicular to sides 1 and 2 of the structure, $F_{1}^{\perp}$ and $F_{2}^{\perp}$, can be obtained using Eq. 10 and Eq. 11, respectively. The $F_{1}^{\perp}$ and $F_{2}^{\perp}$ are then resolved in the $x$ and $y$-direction to obtain the total force in $x$ and $y$-direction, $F_{\text {total }}^{x}$ and $F_{\text {total }}^{y}$, using Eq. 12 through Eq. 15. The following equations describe the calculation of normal and resolved forces related to Fig. 3(b and c). 


$$
\begin{gathered}
F_{i}=P_{i} A_{i} \\
F=\sum F_{i}=\sum_{i}^{n}\left(P_{i} A_{i}\right)
\end{gathered}
$$

217 a. Normal Forces

Normal Force on Side 1:

$$
F_{1}^{\perp}=\sum_{i} p_{i} A_{1 i}
$$

Normal Force on Side 2:

$$
F_{2}^{\perp}=\sum_{i} p_{i} A_{2 i}
$$

b. Resolved Forces in $x$ and $y$-direction:

Force in $x$ and $y$-direction due to $F_{1}^{\perp}$

$$
\begin{gathered}
F_{1}^{x}=F_{1}^{\perp} \sin \theta ; F_{1}^{y}=F_{1}^{\perp} \cos \theta \\
F_{2}^{x}=F_{2}^{\perp} \cos \theta ; F_{2}^{y}=F_{2}^{\perp} \sin \theta \\
F_{\text {total }}^{x}=F_{1}^{x}+F_{2}^{x} \\
F_{\text {total }}^{x}=F_{1}^{\perp} \sin \theta+F_{2}^{\perp} \cos \theta \\
F_{\text {total }}^{y}=F_{1}^{y}-F_{2}^{y}
\end{gathered}
$$

Force in $x$ and $y$-direction due to $F_{2}^{\perp}$

Total Force in $x$-direction

Total Force in $y$-direction

$$
F_{\text {total }}^{y}=F_{1}^{\perp} \cos \theta-F_{2}^{\perp} \sin \theta
$$

In relation to the results of the multiple structures modelling, the determination of force from the SPH pressure output is shown in Fig. 4 since there are differences between rotated and un-rotated structures regarding the expanse of vertical surface impacted by the tsunami bore. Fig. 4( $(\mathrm{a}$ and $\mathrm{b})$ show the water elevations on the vertical surfaces of rotated and unrotated structures during the tsunami inundation, for clarity the surface of the water particles was made semi-transparent by reducing the opacity value by $50 \%$ so that the submerged parts of structures can be visualised. In the example shown in Fig. 4(a) the tsunami bore impact on the rotated structure occurred at two of its vertical faces, with different elevations of water on each side, while on the un-rotated structure with front face parallel to shoreline, the tsunami bore impact was examined on one side only. The numerical force was determined by multiplying the pressure with the loaded area covered by the water elevation that is marked by dashed lines in Fig. 4(c and d), for rotated and un-rotated structures, respectively. The pressures on each impacted face of the structure were measured by equally-spaced numerical pressure probes distributed over the vertical surfaces of the structure. This practice regarding the use of tightly and equally-spaced pressure probes with a certain length of spacing on the surface of a small scale model has been performed experimentally by Fujima et al. (2009). Here, the distance 
between the numerical probes is chosen to be the same as the initial particle spacing. The spacing of pressure probes in all SPH models is the same as the SPH particle spacing $\left(d_{\mathrm{p}}=0.04\right.$ $\mathrm{m})$.

\section{SPH Numerical Modelling: Validation Study}

The numerical model set up shown in Fig. 5, follows the layout of the experimental investigation conducted by Thomas et al. (2015). The tsunami wave basin has a length of 40 $\mathrm{m}$, a width of $8 \mathrm{~m}$ and a height of $2 \mathrm{~m}$. The water tank consists of offshore and onshore parts with two sloping beds (1:15 and 1:30). The offshore region, $0 \leq x \leq 10 \mathrm{~m}$ contains $1 \mathrm{~m}$ depth of fluid particles for water and a moveable paddle wave-maker located at the left-hand side. The instrumentation includes numerical probes placed along the centreline of the water tank for measuring the water surface elevations (i.e. WG2, WG4, WG6) and flow velocities. The numerical pressure probes were mounted on the surface of the structures. At the flat onshore region, a specimen with dimensions of length $L$ and height $H$ giving a structure size of $L \mathrm{x} L \mathrm{x}$ $H=0.6 \times 0.6 \times 0.4 \mathrm{~m}$ representing a building structure was located at $4.8 \mathrm{~m}$ from the shoreline. The vertical front surface of the structure was mounted with numerical pressure probes intended for measuring the impact pressures of tsunami bores. The tsunami-like waves in this study were represented by solitary waves that were generated by paddle movements based on an error function (erf) used in the experiment of Thomas et al. (2015). The solitary wave propagation along the numerical water tank can be seen in Fig. 6. The paddle full displacement was $2 \mathrm{~m}$ and the error function (i.e. erf $=5 \mathrm{~s}$ ) is the time the wave paddle needed to travel the full $2 \mathrm{~m}$ stroke.

The accuracy of the numerical model results was determined by comparing the DualSPHysics model output with the experimental data, comparisons were made for the water surface elevations, velocity and bore run-up. The comparison of water surface elevations focusses on the offshore side by measuring the wave height at WG2, WG4 and WG6. The efficacy of the numerical modelling depends on the SPH particle size $\left(d_{\mathrm{p}}\right)$, so that a particle convergence study to find the appropriate SPH particle size was conducted by comparing numerical and experimental offshore water surface elevations, flow velocity, wave pressure and water surface elevation of the bore. SPH particles of different sizes were tested having inter particle distance, or particle size, $d_{\mathrm{p}}=0.03 \mathrm{~m}, 0.035 \mathrm{~m}, 0.04 \mathrm{~m}$ and $0.05 \mathrm{~m}$, resulting in $8,880,626 ; 6,044,940 ; 4,065,116$ and 2,298,303 particles, respectively. The choice of particle sizes herein was made based on convergence findings from previous investigations 
267 (Cunningham et al. 2014; Pringgana et al. 2016), where the size of SPH particle could be taken as $1 / 10$ of the smallest length of the impacted object.

The comparison of results can be seen in Fig. 7 through Fig. 9. In the experiments, Thomas et al. (2015) report that 50 runs were conducted but only one data set is published and the variability is not reported. Examining the water surface elevations that were measured at WG2, WG4 and WG6, the numerical predictions were lower than the experiment for all particle sizes, $d_{\mathrm{p}}$, as shown in Fig. 7, where the simulation time for each WG was shifted by an equal time interval of $0.3 \mathrm{~s}$ for the clarity of visualisation. The variation of $d_{\mathrm{p}}$ did not significantly affect the offshore water surface elevations. The form of numerical wave seems stable during its propagation for the $15 \mathrm{~m}$ from WG2 to WG4. Fig. 8 shows the maximum flow velocity that was measured by numerical probes placed at an interval of $0.5 \mathrm{~m}$ at the centreline of the wave tank. The numerical flow velocities in were less well predicted compared with the experimental baseline velocity especially before the shoreline where the sea bed is sloping. In Fig. 8, the location of the shoreline and the structure are detailed. Based on the simulation, wave breaking occurred at about $5 \mathrm{~m}$ before the shoreline. In the onshore section, the numerical flow velocity gave closer prediction to the experimental baseline velocity which varied around $2 \mathrm{~m} / \mathrm{s}$. Generally, the numerical flow velocity increased after passing through the shoreline and is approximately constant until just before the structure where it decreases as the bore impacted the surface of structure with a consistent trend with decreasing particle size. The experimental data does not drop in front of the structure but the experimental measurements stop $1 \mathrm{~m}$ from the structure so it is not possible to verify the decrease in velocity predicted by the numerical results.

The numerical water surface elevations as depicted in Fig. 9(a) were measured in front of the structure's surface at a distance of $0.05 \mathrm{~m}$ from the structure and generally show a similar trend to the experimental result, with differences less than $5 \%$ of the experimental results for the peak value, which is expected since the difference is of the order of the particle spacing $O\left(d_{\mathrm{p}}\right)$. After the initial peak surface elevations, the numerical surface elevations decrease similarly to the experimental results but remain slightly greater by $O\left(d_{\mathrm{p}}\right)$. The numerical time simulation of water surface elevations were shifted by $0.5 \mathrm{sec}$ for clarity and the closest water surface elevation peak value was given by the models with $d_{\mathrm{p}}=0.035$ and $0.04 \mathrm{~m}$. Fig. 9(b) shows the numerical prediction of force where the time simulation was shifted so that the numerical maximum force is of the same time with the experimental result. The model with $d_{\mathrm{p}}=0.04 \mathrm{~m}$ gave the closest maximum force value to the experimental result. Simulations with 
$300 d_{\mathrm{p}}=0.03 \mathrm{~m}$ and $0.035 \mathrm{~m}$ over-predicted the experimental results, while the model with $d_{\mathrm{p}}=$ $3010.05 \mathrm{~m}$ gave lower predictions as compared to the test results. Based on the comparisons and 302 given that the variability of the experimental data is not known, it was concluded that the model 303 with $d_{\mathrm{p}}=0.04 \mathrm{~m}$ or $d_{p} / L \approx 1 / 10$ provides the best prediction among others and $d_{\mathrm{p}}=0.04 \mathrm{~m}$ is used for the rest of the numerical modelling in this study.

The other SPH modelling constants and parameters in DualSPHysics are summarised in Table 1, further details on the basis of the SPH parameters can be found in (Gomez-Gesteira et al. 2012b). All SPH simulations were run using commercial GPU hardware, Nvidia GeForce GTX 1060, which has $6144 \mathrm{MB}$ memory and $1.77 \mathrm{GHz}$ clock rate. The time of simulation and the number of particles involved in the simulations for all cases with $d_{\mathrm{p}}=0.04 \mathrm{~m}$ including those presented in the following sections are summarised in Table 2. The validation case as explained above and the extended cases presented in the following sections were simulated for 25 seconds, where the analysis run times per second simulation were varied from $455.75 \mathrm{sec}$. to $470.43 \mathrm{sec}$. The SPH particles involved in the simulations were divided into fixed boundary (water tank, cube structures, measuring probes), moving boundary (paddle wave-maker) and fluid particles (tsunami wave). All cases have the same number of particles for the moving boundary and the fluid particles, but vary for the fixed boundary according to the number of cube structures in each modelling case.

\section{SPH Numerical Modelling: Extended modelling}

Following the validation with a single structure, extended models are now performed involving multiple structures as investigated experimentally by Thomas et al. (2015) to study the tsunami flow characteristics and the associated tsunami impact forces on the structures. The structures' position could provide positive or negative effects on neighbouring structures during tsunami events due to the previously described shielding or flow focusing effects as witnessed in the 2011 Japan tsunami and elsewhere (Goseberg 2013; Robertson et al. 2013). The numerical investigation goes further than Thomas et al. (2015) by examining the effect of rotated arrangements. In this section, these effects will be examined numerically and discussed.

\section{Multiple Structures (Orthogonal Orientation)}

The extended SPH models are shown in Fig. 10 with tank size similar to that shown in Fig. 5. Since the main interest is on the area near the shoreline where the interaction between tsunami bore and structures occurs, the plan (top view) of the water tank shows only the region from $x=30 \mathrm{~m}$ to $x=40 \mathrm{~m}$. In the SPH water tank, the tsunami-like wave propagates in the $x$ - 
direction, passing the shoreline and then hits the onshore structures that sit on the flat shore. All three structures have the same size of $0.6 \mathrm{~m} \times 0.6 \mathrm{~m}$ with $0.4 \mathrm{~m}$ height, where two front structures, $\mathrm{S} 1$ and $\mathrm{S} 2$, provide protection to the rear structure and S3 becomes the main impact target. The arrangement of those structures is based on the wake-clearance-angle that was originally denoted as $\beta$ in Thomas et al. (2015), however, in the current paper this is denoted as A. Fig. 10(a, b, c and d), show structures with $\mathrm{A}=3.6^{\circ}, 9.5^{\circ}, 32^{\circ}$ and $37^{\circ}$, respectively.

The four dots marked as P1, P2, P3 and P4 are the probes to measure the water surface elevations and the velocities of tsunami flow. Cases shown in Fig. 10(a, b and c), correspond to the cases reported in Thomas et al. (2015) so that direct comparison between the experimental and numerical results can be performed. The modelling case with $\mathrm{A}=37^{\circ}$ including structure S1, S2 and S3 as shown in Fig. 10(d) is also taken from Thomas et al. (2015), however, the results were not experimentally reported. Further modifications are then made by adding structures S4 and S5 to resemble a real-life scenario where building structures occupy a regular spacing arrangement for instance, as shown by satellite images of the ToniHongo village in Suppasri et al. (2012) and experimentally investigated by Goseberg (2013), in contrast with the cases shown in Fig. 10(a, b and c). The case shown in Fig. 10(d) can provide new insight into the hydrodynamic characteristics and effects on the structures behind the main impact target (S3).

\section{Multiple Rotated Structures}

To study the effect of orientation of structures depending on the oncoming tsunami wave direction, the configuration of multiple structures rotated about their vertical axis were made as shown in Fig. 10(e and f). Fig. 10(e) shows an example of an orientation case where the front structures S1 and S2 are rotated inward, while the main structure, S3, remains unrotated to observe the force applied on the vertical front surface of S3. The variations related to Fig. 10(e) were the rotation of S1 and S2 equal to $30^{\circ}, 45^{\circ}$ and $60^{\circ}$ inward and the wake clearance angle, $\mathrm{A}=3.6^{\circ}, 9.5^{\circ}$ and $32^{\circ}$, resulting in 9 different cases. Further studies on structure orientations were made by rotating five structures, S1 to S5, clockwise as shown in Fig. 10(f) by angles of $15^{\circ}, 30^{\circ}$ and $45^{\circ}$, following the un-rotated version previously shown in Fig. 10(d). Regarding Fig. 10(f), the $60^{\circ}$ final position of the rotated structures is similar to the horizontally-mirrored $30^{\circ}$ versions, so that the $60^{\circ}$ rotation was not created for this case. All numerical simulations that will be performed in this study are summarised in Table 3. 
365

366

367

368

369

370

371

372

373

374

375

376

377

378

379

380

381

382

383

384

385

386

387

388

389

390

391

392

393

394

395

The simulation of onshore bore flows around building structures for varying values of wake clearance angle (A) can be seen in Fig. 11. The colour of the water particles is based on the flow velocity. In all figures with bore flows, the arrows act as a vector that represents the direction of bore flows and the size of the arrows corresponds to the magnitude of flow velocity. The colour of the arrows was set to a different colour map to contrast with the colour of bore flows. The simulation snapshot was taken at $t=19.3 \mathrm{sec}$. to provide insight into the flow that has passed through the front structures S1 and S2 and then impacted the main structure S3 as shown by Fig. 11(a, b and c). The gap between S1 and S2 in Fig. 11( $a$ and b) is the same, however, by setting S1 and S2 farther away, closer to the shoreline, the impact to S3 is minimised since the bore flow that passed through the gap was scattered. A wide gap between S1 and S2 as shown by Fig. 11(c) clearly leads to a greater volume of water impacting on S3. To provide more detail on the bore propagation and its interaction with the structures, Fig. 12 in relation with Fig. 11(b), shows the time sequence before the bore reaches the front structures (a), when the bore has just started to collide with the front structures (b) and after the bore impacts the main structure, S3, (c) further than what is shown in Fig. 11(b). Note that the range of flow velocity and velocity vector in Fig. 12 is the same to that of Fig. 11.

The tsunami flow velocities depicted in Fig. 13 generally show that the highest flow velocities at all probes occurs in the model with $\mathrm{A}=3.6^{\circ}$ in relation to the layout in Fig 10(a) and the simulation in Fig. 11(a). The small gap of S1 and S2 focuses the bore flows thus increasing the velocity. The close prediction between dashed $\left(\mathrm{A}=9.5^{\circ}\right)$ and dotted lines $\left(\mathrm{A}=32^{\circ}\right)$ in Fig. 13(a) occurred because probe $\mathrm{P} 1$ was undisturbed, being situated seaward of the most seaward structure, as shown in Fig. 10(b and c). In Fig. 13(b) at the beginning, the dashed and dotted lines are close, however, they were immediately separated because at probe P2 the bore flow decelerated. This was due to the accumulation of water particles clearly shown by the sharply decreased velocity of the dashed line as the bore flows through the smaller gap between S1 and S2, see Fig. 11(b).

Fig. 14 shows the comparison of the numerical total forces $\left(F_{\text {total }}^{x}\right)$ exerted on the vertical surface of the target structures for cases with different wake clearance angle (A). Fig. 14(a) depicts the numerical total force on S3 based on different A values. The published experimental data in Thomas et al. (2015) enables the direct comparison with numerical force prediction for each A value, as shown in Fig. 14(b, c and d). 
396

397

398

399

400

401

402

403

404

405

406

407

408

409

410

411

412

413

414

415

416

417

418

419

420

421

422

423

424

425

426

427

428

The graph's legend in Fig. 14 consecutively indicates the wake clearance angle (A), the rotation (R) and the impacted structure (S). For example, A32_R0_S3 means a model with $32^{\circ}$ wake clearance angle, $0^{\circ}$ rotation (un-rotated), and structure S3 where the force is applied. Fig. 14(b) shows the highest total force result, both numerical and experimental, for $\mathrm{A}=32^{\circ}$ with the associated flow visualisation in Fig. 11(c). Fig. 14(b) and (c) show that generally the numerical models predict the experimental results, with differences on maximum values of $3.4 \%$ and $7.5 \%$, respectively. In Fig. 14(d), the peak numerical force is only 6\% lower than the experiment, however, the post-peak force is significantly lower than the experiment. This occurred because of the small number of water particles that passed through the gap between $\mathrm{S} 1$ and $\mathrm{S} 2$, where the length of the gap is only $15 d_{\mathrm{p}}$. The numerical time simulations were shifted to match the experimental time simulation. In general numerical post-peak behaviour for all simulations shows a similar pattern to the corresponding experimental data of Thomas et al. (2015).

\section{Modelling Results of Multiple Rotated Structures}

Extending the experiments of Thomas et al. (2015), Fig. 15 show the simulation results for the multiple inward-rotated front structures, S1 and S2, where the main structure, S3, remained un-rotated. Fig. 15 demonstrates the simulation of the $45^{\circ}$ rotation (R45) for different wake clearance angles $\left(\mathrm{A}=3.6^{\circ}, \mathrm{A}=9.5^{\circ}, \mathrm{A}=32^{\circ}\right)$. From simple geometry it is clear that the gap between $S 1$ and $S 2$ decreases when both structures are rotated $45^{\circ}$, Fig. 15(a and b), this results in more scattered bore flows as compared to the corresponding un-rotated case in Fig. 11( $\mathrm{a}$ and $\mathrm{b})$. For the total force $\left(F_{\text {total }}^{x}\right)$ comparison, the series in Fig. 14(a) were re-produced as black solid lines in Fig. 16(a, b and c). For small wake clearance angles of $\mathrm{A}=3.6^{\circ}$ and $9.5^{\circ}$ it can be seen from Fig. 16(a and b) that the inward-rotation of the front structures S1 and S2 for all rotations $\left(\mathrm{R}=30^{\circ}, 45^{\circ}, 60^{\circ}\right)$ was effective in reducing the total force on S3. In contrast Fig. 16(c) shows that for the wide S1-S2 gap $\left(A=32^{\circ}\right)$, all inward-rotation cases $\left(R=30^{\circ}, 45^{\circ}\right.$, $60^{\circ}$ ) produced progressively greater total force on S3. The maximum force values on S3 for multiple rotated structure cases can be seen in Table 4 .

The numerical modelling results of the multiple structures rotated all clockwise, with $\mathrm{A}=37^{\circ}$, are presented in Fig. 17 to Fig. 20. The numerical simulations based on $\mathrm{R}=0^{\circ}, 15^{\circ}$, $30^{\circ}$ and $45^{\circ}$ cases are depicted in Fig. 17 which shows the stage at $t=19.3 \mathrm{sec}$ as the tsunami bore impacts the front two structures S1 and S2 the main structure S3 and the rear structures S4 and S5. In Fig. 18, the main structures (S3) in all rotation cases acquired higher impact forces compared with structures S1 and S2 at the first row, demonstrating a flow focussing 
effect with this arrangement. As previously predicted, structures in the last row, S4 and S5, are also influenced by the bore flows but to a much lesser degree given the resulting force values.

For the rotated structures, the influence of the resultant $y$-direction forces may become significant, these are shown for $15^{\circ}, 30^{\circ}$ and $45^{\circ}$ rotations in figure $18(\mathrm{e})$. The negative force resultant values given by the $15^{\circ}$ and $30^{\circ}$ cases indicate that the structure experiences global leftwards force perpendicular to the tsunami direction. For the case with $\mathrm{R}=45^{\circ}$ in Fig. $17(\mathrm{~d})$, the resultant $y$-direction force was approximately zero as expected with some small fluctuation over the time period. When the force predictions for all front structures were compared, taking $\mathrm{S} 1$ as an example, Fig. 19(a) shows that the rotation of $\mathrm{R} 15^{\circ}$ and $\mathrm{R} 30^{\circ}$ returned higher force predictions than the $\mathrm{R} 45^{\circ}$ case. Considering the main structure, $\mathrm{S} 3$, all rotations $\mathrm{R} 0^{\circ}, \mathrm{R} 15^{\circ}$, $\mathrm{R} 45^{\circ}$ gave insignificant differences regarding the total forces, as shown by Fig. 19. The maximum total forces on the front and main structures can be seen in Table 5 .

Fig. 20 shows views inside the numerical water tank, from the landward side of structure S3 looking seaward. The images were made by setting the surfaces of S3 to be completely transparent and depicting the body of S3 as a wireframe. Fig. 20(a) and Fig. 20(b) differentiated by an angle of rotation $\mathrm{R} 0^{\circ}$ and $\mathrm{R} 45^{\circ}$, respectively, visualize the $\mathrm{SPH}$ simulation at the stages when the maximum pressure of the tsunami bore occurred and the location of maximum pressure is marked by the hollow black circles. The tsunami bore developed as the wave propagated onshore and in Fig. 20 the snapshots of bore impact can be seen on the vertical surface(s) of S3 following the impact. The bore pressure and water elevation were measured by probes indicated by black dots mounted on the vertical surface(s) of S3. The maximum pressure values at simulation stages corresponding to Fig. 20(a) and Fig. 20(b) were $7564 \mathrm{~Pa}$ and $5032 \mathrm{~Pa}$, respectively, however the maximum contour value in Fig. 20(a and b) were set to $1600 \mathrm{~Pa}$ for a clearer view of pressure distribution across the surfaces of the structure due to available colour gradations. The results indicate that rotating the structure shifts the location of peak impact pressure from the central region of the face to the corner.

\section{Discussion of limitations and implications}

Due to the huge parameter space (different parameters such as structure separation, rotation, hydrodynamics conditions, etc., and the value range of each parameter), this study is unable to encompass the entire possible structure arrangements and hydrodynamic conditions encountered in the field, thus the numerical findings are limited by the scope of investigation. Moreover, the cases used for numerical validation and variation were decided based on the 
461

462

463

464

465

466

467

468

469

470

471

472

473

474

475

476

477

478

479

480

481

482

483

484

485

486

487

488

489

490

491

492

availability of experimental data found in the literature whose variability or repeatability needs closer examination. Although a convergence study was undertaken, the fidelity of the numerical prediction may be affected by the model resolution, but for a much greater resolution the simulation time is prohibitive with current computing capability.

In the development of coastal master plans and the resilience of building structures in tsunami events, numerical tools offer useful insights into the wave and structure interaction (Peyronnin et al. 2013). The work presented in the current study indicates that the strategic positioning of structures can lead to significant reduction in tsunami forces. In the case of existing coastal communities, it may be the case that significant strengthening of a limited number of seaward located structures may be an economic way of protecting structures landward of these. Similarly, the introduction of discrete, discontinuous defensive walls onshore to influence the inundation flow characteristics may be a further economic option in areas prone to tsunamis as opposed to large scale continuous sea walls.

\section{Conclusion}

Numerical modelling using SPH was conducted to study the influence of onshore structure orientations on the total forces applied to the structure from tsunami bores. The validation was performed using the experimental data of Thomas et al. (2015) and this formed the basis for extended modelling varying both the wake clearance angle (A) and the on-plan rotation $(\mathrm{R})$ of structures. The following conclusions can be made based on the numerical modelling results.

1. The validation model with particle size of $d_{p} / L \approx 1 / 10,\left(d_{p}=0.04 \mathrm{~m}\right)$ provides closest results to the experimental data, following the comparison of the wave gauge data, water surface elevation, wave run-up, flow velocity and force. The accuracy of the numerical model was demonstrated by close prediction within $7.5 \%$ of maximum numerical and experimental forces on the main structure $(\mathrm{S} 3)$ for the un-rotated case $(\mathrm{R}=0)$ with $\mathrm{A}=3.6^{\circ}, 9.5^{\circ}, 32^{\circ}$.

2. In the inward-rotation cases, the angles of separation of $\mathrm{A}$ of $3.6^{\circ}, 9.5^{\circ}, 32^{\circ}$ were combined with rotation of $\mathrm{R}=30^{\circ}, 45^{\circ}$ and $60^{\circ}$. The results indicate that closer-distance seaward structures $\left(\mathrm{A}=3.6^{\circ}\right.$ and $\left.9.5^{\circ}\right)$ provide a shielding effect and reduce the total forces on the main target structure regardless of the rotations ( $\mathrm{R}$ values) of the front shielding structures, when compared to the baseline.

3. In the models with a larger wake clearance angle of $\mathrm{A}=32^{\circ}$, the total forces on the main target structures were higher than the baseline for all rotations ( $\mathrm{R}$ values) of the front 
shielding structures and the increase of total forces is directly proportional to the increase of $\mathrm{R}$ values. For design purposes, this suggests the existence of a maximum wake clearance angle A to limit forces on a target structure.

4. In the clockwise-rotation case models, the A value was $37^{\circ}$ and combined with $\mathrm{R}$ values of $15^{\circ}, 30^{\circ}$ and $45^{\circ}$. The results show that the orientations of structures effectively reduced the total forces on all structures, where the total force values are inversely proportional to the $\mathrm{R}$ values.

The numerical model SPH is able to provide information on the spatial and temporal distribution of pressure on the vertical surfaces of the structures during the violent bore propagation and impact process. This approach can provide an efficient modelling tool to improve structural design of key elements in the drive towards tsunami resilience. Although limited to the particular geometry and tsunami bore characteristics examined, the results offer some insights into the variation of damage observed in real life tsunamis and suggest the influence of spatial distribution and orientation of building structures merits future detailed study. In particular, the potential creation of discrete, strategic strong points within the built environment to create shelter for adjacent structures may be an attractive and economic option for coastal communities in tsunami prone regions of the world.

\section{Data Availability Statement}

The output data presented in this study has been made electronically available to readers. Further data is available on request.

\section{Acknowledgements}

The authors gratefully acknowledge the support of the Faculty of Engineering at Udayana University, Indonesia and the Department of Mechanical, Aerospace and Civil Engineering at the University of Manchester, UK.

\section{REFERENCES}

Alongi, D. M. (2008). "Mangrove forests: Resilience, protection from tsunamis, and responses to global climate change." Estuarine, Coastal and Shelf Science, 76, 1-13, https://doi.org/10.1016/j.ecss.2007.08.024.

Altomare, C., Crespo, A. J. C. A. J. C., Domínguez, J. M. J. M., Gómez-Gesteira, M., Suzuki, T., and Verwaest, T. (2015). "Applicability of Smoothed Particle Hydrodynamics for estimation of sea wave impact on coastal structures." Coastal Engineering, Elsevier B.V., 96, 1-12, https://doi.org/10.1016/j.coastaleng.2014.11.001.

Antuono, M., Marrone, S., Colagrossi, A., and Bouscasse, B. (2015). "Energy balance in the 
$\delta$-SPH scheme." Comput. Methods Appl. Mech. Engrg., 289, 209-226, https://doi.org/10.1016/j.cma.2015.02.004.

ASCE/SEI 7-16. (2017). Minimum Design Loads and Associated Criteria for Buildings and Other Structures. American Society of Civil Engineer, Reston, VA.

Baines, A., Watson, P., Cunningham, L. S., Rogers, B. D., Murphy, J., and Lizondo, S. (2019). "Modelling shore-side pressure distributions from violent wave breaking at a seawall." Proceedings of the Institution of Civil Engineers: Engineering and Computational Mechanics, 172(3), 118-123, https://doi.org/10.1680/jencm.19.00007.

Barreiro, A., Crespo, A. J. C., Domínguez, J. M., and Gómez-Gesteira, M. (2013). "Smoothed Particle Hydrodynamics for coastal engineering problems." Computers \& Structures, Elsevier Ltd, 120, 96-106, https://doi.org/10.1016/j.compstruc.2013.02.010.

Chinnarasri, C., Thanasisathit, N., Ruangrassamee, A., Weesakul, S., and Lukkunaprasit, P. (2013). "The Impact of Tsunami-Induced Bores on Buildings." Maritime Engineering, 166, 14-24, https://doi.org/10.1680/maen.2010.31.

Chock, G., Carden, L., Robertson, I., Olsen, M., and Yu, G. (2013). "Tohoku tsunami-induced building failure analysis with implications for U.S. tsunami and seismic design codes." Earthquake Spectra, 29, https://doi.org/10.1193/1.4000113.

Cox, D., Tomita, T., Lynett, P., and Holman, R. (2008). "Tsunami inundation with macroroughness in the constructed environment." Proceedings of the 31st International Conference on Coastal Engineering, 1421-1432, https://doi.org/10.1142/9789814277426_0118.

Crespo, A. J. C., Domínguez, J. M., Rogers, B. D., Gómez-Gesteira, M., Longshaw, S., Canelas, R., Vacondio, R., Barreiro, A., and García-Feal, O. (2015). "DualSPHysics: Opensource parallel CFD solver based on Smoothed Particle Hydrodynamics (SPH)." Computer Physics Communications, Elsevier B.V., 187, 204-216, https://doi.org/10.1016/j.cpc.2014.10.004.

Cunningham, L. S., Rogers, B. D., and Pringgana, G. (2014). "Tsunami wave and structure interaction: an investigation with smoothed-particle hydrodynamics." ICE Journal of Engineering and Computational Mechanics, 167(EM3), 126-138, https://doi.org/10.1680/eacm.13.00028.

Dias, W. P. S., and Mallikarachchi, H. M. Y. C. (2006). "Tsunami - Planning and design for disaster mitigation." Structural Engineer, 84(11), 25-29.

FEMA, and FEMA (Federal Emergency Management Agency). (2011). Coastal Construction Manual. FEMA P-55, (3 vols.) 3rd ed. (FEMA 55). Federal Emergency Management Agency, Jessup, MD., Washington, DC, USA.

Fujima, K., Achmad, F., Shigihara, Y., and Mizutani, N. (2009). "A Study on Estimation of Tsunami Force Acting on Structures.” Journal of Disaster Research, 4(6), 404-409.

Ghobarah, A., Saatcioglu, M., and Nistor, I. (2006). "The Impact of the 26 December 2004 Earthquake and Tsunami on Structures and Infrastructure." Engineering Structures, 28, 312-326, https://doi.org/10.1016/j.engstruct.2005.09.028.

Ghosh, D., Mittal, A. K., and Bhattacharyya, S. K. (2016). "Multiphase modeling of tsunami impact on building with openings." Journal of Computational Multiphase Flows, 8(2), 8594, https://doi.org/10.1177/0010836716653881.

Gomez-Gesteira, M., Crespo, A. J. C., Rogers, B. D., Dalrymple, R. A., Dominguez, J. M., and Barreiro, A. (2012a). "SPHysics - development of a free-surface fluid solver - Part 2: Efficiency and test cases." Computers and Geosciences, Elsevier, 48(2), 300-307, https://doi.org/10.1016/j.cageo.2012.02.028.

Gomez-Gesteira, M., Rogers, B. D., Crespo, A. J. C., Dalrymple, R. A., Narayanaswamy, M., and Dominguez, J. M. (2012b). "SPHysics - development of a free-surface fluid solver Part 1: Theory and formulations." Computers \& Geosciences, Elsevier, 48(1), 289-299, 
601

602

603

604

605

606

607

608

609

610

611

612

613

614

615

616

617

618

619

620

621

622

623

624

625 https://doi.org/10.1016/j.cageo.2012.02.029.

Goseberg, N. (2013). "Reduction of maximum tsunami run-up due to the interaction with beachfront development - Application of single sinusoidal waves." Natural Hazards and Earth System Sciences, 13(11), 2991-3010, https://doi.org/10.5194/nhess-13-2991-2013.

Goseberg, N., and Schlurmann, T. (2012). "Interaction of idealized urban infrastructure and long waves during run-up and on-land flow process in coastal regions." Proceedings of the Coastal Engineering Conference, https://doi.org/10.9753/icce.v33.currents.18.

Hartana, and Murakami, K. (2015). "Numerical and Experimental Simulation of Two-Phase Tsunami Flow Through Buildings with Openings." Journal of Earthquake and Tsunami, 09(03), 1550007, https://doi.org/10.1142/S1793431115500074.

Imamura, F., Boret, S. P., Suppasri, A., and Muhari, A. (2019). "Recent occurrences of serious tsunami damage and the future challenges of tsunami disaster risk reduction." Progress in Disaster Science, 1, 100009, https://doi.org/10.1016/j.pdisas.2019.100009.

Kihara, N., Niida, Y., Takabatake, D., Kaida, H., Shibayama, A., and Miyagawa, Y. (2015). "Large-scale experiments on tsunami-induced pressure on a vertical tide wall." Coastal Engineering, Elsevier B.V., 99, 46-63, https://doi.org/10.1016/j.coastaleng.2015.02.009.

Lau, T. L., Choong, K. K., Majid, T. A., Zakaria, N. A., Ab. Ghani, A., and Inoue, S. (2015). "Estimation of Tsunami Force for Onshore Buildings in the Northwest Coast of Peninsular Malaysia." Applied Mechanics and Materials, 802, 172-177, https://doi.org/10.4028/www.scientific.net/AMM.802.172.

Leelawat, N., Suppasri, A., and Imamura, F. (2015). "Disaster Recovery and Reconstruction Following the 2011 Great East Japan Earthquake and Tsunami: A Business Process Management Perspective." International Journal of Disaster Risk Science, Beijing Normal University Press, 6(3), 310-314, https://doi.org/10.1007/s13753-015-0066-1.

Leone, F., Lavigne, F., Paris, R., Denain, J. C., and Vinet, F. (2011). “A Spatial Analysis of The December 26th, 2004 Tsunami-Induced Damages: Lessons Learned for A Better Risk Assessment Integrating Buildings Vulnerability." Applied Geography, 31, 363-375, https://doi.org/10.1016/j.apgeog.2010.07.009.

Levy, J. K., and Gopalakrishnan, C. (2005). "Promoting Disaster-resilient Communities: The Great Sumatra-Andaman Earthquake of 26 December 2004 and the Resulting Indian Ocean Tsunami." International Journal of Water Resources Development, 21(4), 543-559, https://doi.org/10.1080/07900620500363297.

Lukkunaprasit, P., Ruangrassamee, A., and Thanasisathit, N. (2009). "Tsunami Loading on Buildings with Openings.” Journal of Tsunami Society International, 28(5), 303-310.

Lynett, P. J., Wu, T. R., and Liu, P. L. F. (2002). "Modeling wave runup with depth-integrated equations." Coastal Engineering, 46(2), 89-107, https://doi.org/doi.org/10.1016/S03783839(02)00043-1.

Macabuag, J., Raby, A., Pomonis, A., Nistor, I., Wilkinson, S., and Rossetto, T. (2018). "Tsunami design procedures for engineered buildings: A critical review." Proceedings of the Institution of Civil Engineers: Civil Engineering, 171(4), 166-178, https://doi.org/10.1680/jcien.17.00043.

Marrone, S., Antuono, M., Colagrossi, A., Colicchio, G., Le Touzé, D., and Graziani, G. (2011). " $\delta$-SPH model for simulating violent impact flows." Computer Methods in Applied Mechanics and Engineering, 200(13), 1526-1542, https://doi.org/10.1016/j.cma.2010.12.016.

Mikami, T., Shibayama, T., and Esteban, M. (2012). "Field Survey of the 2011 Tohoku Earthquake and Tsunami in Miyagi and Fukushima Prefectures." Coastal Engineering Journal, 54, 1-26, https://doi.org/10.1142/S0578563412500118.

Monaghan, J. J. (1994). "Simulating Free Surface Flows with SPH.” Journal of Computational Physics. 
Moon, W. C., Chiew, L. Q., Cheong, K. W., Tee, Y. C., Chun, J. B., and Lau, T. L. (2019). "An experimental study for estimating tsunami wave forces acting on building with seaward and landward macroroughness." Ocean Engineering, 186(June), 10, https://doi.org/10.1016/j.oceaneng.2019.106116.

Morin, J., Coster, B. De, Paris, R., Flohic, F., Floch, D. Le, and Lavigne, F. (2008). "Tsunamiresilient communities' development in Indonesia through educative actions: Lessons from the 26 December 2004 tsunami." Disaster Prevention and Management, 17(3), 430-446, https://doi.org/10.1108/09653560810887338.

Murty, T. S., Rao, A. D., Nirupama, N., and Nistor, I. (2006). "Numerical modelling concepts for tsunami warning systems." Current Science, 90(8), 1073-1081.

Park, H., Cox, D. T., Lynett, P. J., Wiebe, D. M., and Shin, S. (2013). "Tsunami inundation modeling in constructed environments: A physical and numerical comparison of freesurface elevation, velocity, and momentum flux." Coastal Engineering, Elsevier B.V., 79, 9-21, https://doi.org/10.1016/j.coastaleng.2013.04.002.

Park, H., Tomiczek, T., Cox, D. T., van de Lindt, J. W., and Lomonaco, P. (2017). "Experimental modeling of horizontal and vertical wave forces on an elevated coastal structure." Coastal Engineering, Elsevier Ltd, 128(August), 58-74, https://doi.org/10.1016/j.coastaleng.2017.08.001.

Petrone, C., Rossetto, T., Baiguera, M., la Barra Bustamante, C. De, and Ioannou, I. (2020). "Fragility functions for a reinforced concrete structure subjected to earthquake and tsunami in sequence." Engineering Structures, Elsevier, 205(December 2019), 110120, https://doi.org/10.1016/j.engstruct.2019.110120.

Peyronnin, N., Green, M., Richards, C. P., Owens, A., Reed, D., Chamberlain, J., Groves, D. G., Rhinehart, W. K., and Belhadjali, K. (2013). "Louisiana's 2012 Coastal Master Plan: Overview of a Science-Based and Publicly Informed Decision-Making Process." Journal of Coastal Research, (67), 1-15, https://doi.org/10.2112/SI_67_1.1.

Pringgana, G., Cunningham, L. S., and Rogers, B. D. (2016). "Modelling of tsunami-induced bore and structure interaction." Proceedings of the Institution of Civil EngineersEngineering and Computational Mechanics, 169(EM3), 109-125, https://doi.org/10.1680/jencm.15.00020.

Qin, X., Motley, M. R., and Marafi, N. A. (2018). "Three-dimensional modeling of tsunami forces on coastal communities." Coastal Engineering, 140, 43-59, https://doi.org/10.1016/j.coastaleng.2018.06.008.

Rabinovich, A. B., Thomson, R. E., and Stephenson, F. E. (2006). "The Sumatra tsunami of 26 December 2004 as observed in the North Pacific and North Atlantic oceans." Surveys in Geophysics, 27(6), 647-677, https://doi.org/10.1007/s10712-006-9000-9.

Robertson, I., Riggs, H. R., and Chock, G. (2013). "Development of Tsunami Design Provisions Webinar." Network for Earthquake Engineering Simulation (NEES), Purdue University, West Lafayette, IN, USA., <https://nees.org/resources/6277> (Apr. 10, 2020).

Rossetto, T., De la Barra, C., Petrone, C., De la Llera, J. C., Vásquez, J., and Baiguera, M. (2019). "Comparative assessment of nonlinear static and dynamic methods for analysing building response under sequential earthquake and tsunami." Earthquake Engineering and Structural Dynamics, 48(8), 867-887, https://doi.org/10.1002/eqe.3167.

Saatcioglu, M., Ghobarah, A., and Nistor, I. (2005). "Effects of the December 26, 2004 Sumatra Earthquake and Tsunami on Physical Infrastructure." ISET Journal of Earthquake Technology, 42, 79-94.

St-Germain, P., Nistor, I., Townsend, R., and Shibayama, T. (2014). "Smoothed-Particle Hydrodynamics Numerical Modeling of Structures Impacted by Tsunami Bores." Journal of Waterway, Port, Coastal, and Ocean Engineering, 140(1), 66-81, https://doi.org/10.1061/(ASCE)WW.1943-5460.0000225. 
Suppasri, A., Goto, K., Muhari, A., Ranasinghe, P., Riyaz, M., Affan, M., Mas, E., Yasuda, M., and Imamura, F. (2015). "A Decade After the 2004 Indian Ocean Tsunami: The Progress in Disaster Preparedness and Future Challenges in Indonesia, Sri Lanka, Thailand and the Maldives." Pure and Applied Geophysics, 172(12), 3313-3341, https://doi.org/10.1007/s00024-015-1134-6.

Suppasri, A., Mas, E., Charvet, I., Gunasekera, R., Imai, K., Fukutani, Y., Abe, Y., and Imamura, F. (2013). "Building damage characteristics based on surveyed data and fragility curves of the 2011 Great East Japan tsunami." Natural Hazards, 66(2), 319-341, https://doi.org/10.1007/s11069-012-0487-8.

Suppasri, A., Shuto, N., Imamura, F., Koshimura, S., Mas, E., and Yalciner, A. C. (2012). "Lessons Learned from the 2011 Great East Japan Tsunami: Performance of Tsunami Countermeasures, Coastal Buildings, and Tsunami Evacuation in Japan." Pure and Applied Geophysics, 170(6), 993-1018, https://doi.org/10.1007/s00024-012-0511-7.

Syamsidik, Benazir, Luthfi, M., Suppasri, A., and Comfort, L. K. (2020). "The 22 December 2018 Mount Anak Krakatau Volcanogenic Tsunami on Sunda Strait Coasts, Indonesia: tsunami and damage characteristics." Natural Hazards and Earth System Sciences Discussions, 20, 549-565, https://doi.org/10.5194/nhess-20-549-2020.

Syamsidik, Benazir, Umar, M., Margaglio, G., and Fitrayansyah, A. (2019). "Post-tsunami survey of the 28 September 2018 tsunami near Palu Bay in Central Sulawesi, Indonesia: Impacts and Challenges to coastal communities." International Journal of Disaster Risk Reduction, 38(101229), 1-13.

Thomas, S., Killian, J., and Bridges, K. (2015). "Influence of Macroroughness on Tsunami Loading of Coastal Structures." Journal of Waterway, Port, Coastal and Ocean Engineering, 141(1), 1-14, https://doi.org/10.1061/(ASCE)WW.1943- 5460.0000268.

Thusyanthan, N. I., and Madabhushi, S. P. G. (2008). "Tsunami wave loading on coastal houses: a model approach." Proceedings of the ICE - Civil Engineering, 161(2), 77-86, https://doi.org/10.1680/cien.2008.161.2.77.

Tomiczek, T., Prasetyo, A., Mori, N., Yasuda, T., and Kennedy, A. (2016). "Physical modelling of tsunami onshore propagation, peak pressures, and shielding effects in an urban building array." Coastal Engineering, Elsevier B.V., 117, 97-112, https://doi.org/10.1016/j.coastaleng.2016.07.003.

Tomiczek, T., Prasetyo, A., Mori, N., Yasuda, T., and Kennedy, A. (2017). "Effects of a macroroughness element on tsunami wave amplification, pressures, and loads: Physical model and comparison to Japanese and US Design Equations." Coastal Engineering Journal, 59(1), https://doi.org/10.1142/S0578563417500048.

Tomiczek, T., Wyman, A., Park, H., and Cox, D. T. (2019). "Modified Goda Equations to Predict Pressure Distribution and Horizontal Forces for Design of Elevated Coastal Structures." Journal of Waterway, Port, Coastal and Ocean Engineering, 145(6), 1-16, https://doi.org/10.1061/(ASCE)WW.1943-5460.0000527.

Tomita, T., Honda, K., and Kakinuma, T. (2006). "Application of three-dimensional tsunami simulator to estimation of tsunami behavior around structures." Proc., 30th Int. Conf. on Coastal Engineering, J. M. Smith, ed., 1677-1688.

Triatmadja, R., and Nurhasanah, A. (2012). "Tsunami force on buildings with openings and protection." Journal of Earthquake and Tsunami, 6(4), 1-17, https://doi.org/10.1142/S1793431112500248.

Violeau, D., and Rogers, B. D. (2016). "Smoothed particle hydrodynamics (SPH) for freesurface flows: past, present and future." Journal of Hydraulic Research, 54(1), 1-26, https://doi.org/10.1080/00221686.2015.1119209.

Wendland, H. (1995). "Piecewise polynomial, positive definite and compactly supported radial functions of minimal degree." Advanc. Comput. Math., 4(1), 389-396. 
Wilson, J. S., Gupta, R., van de Lindt, J. W., Clauson, M., and Garcia, R. (2009). "Behavior of a One-Sixth Scale Wood-Framed Residential Structure under Wave Loading." Journal of

Constructed

Facilities,

23(5),

336-345, https://doi.org/10.1061/(ASCE)CF.1943-5509.0000039. 

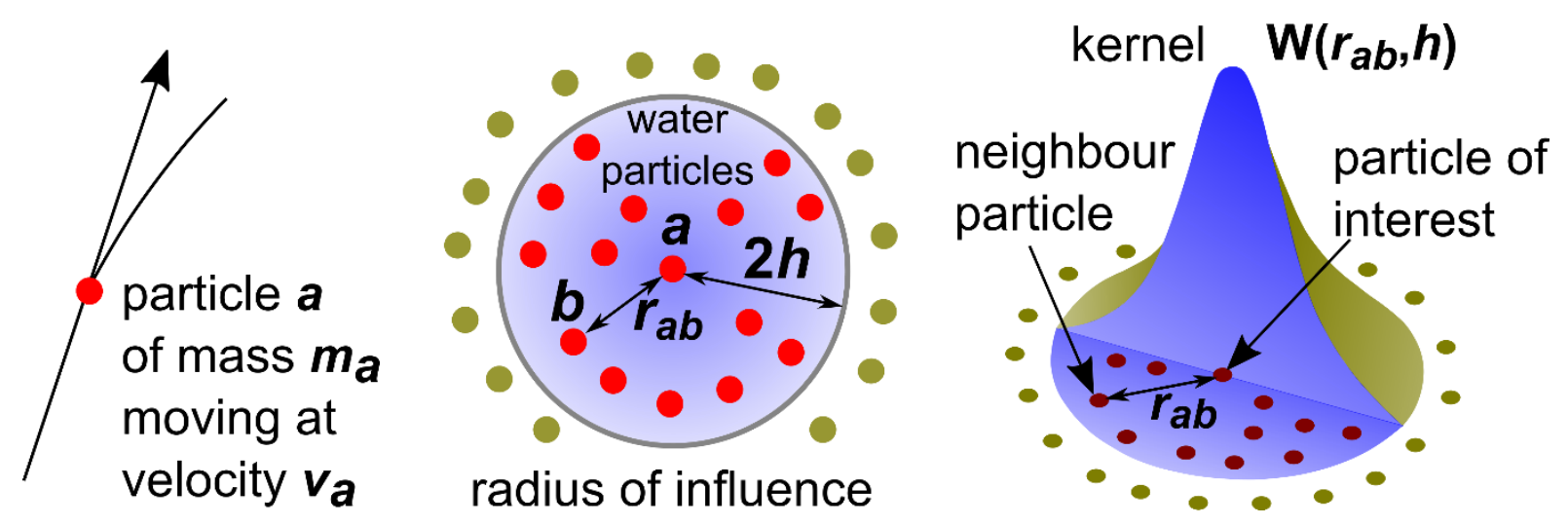

Fig. 1. Diagram of the SPH smoothing kernel. 


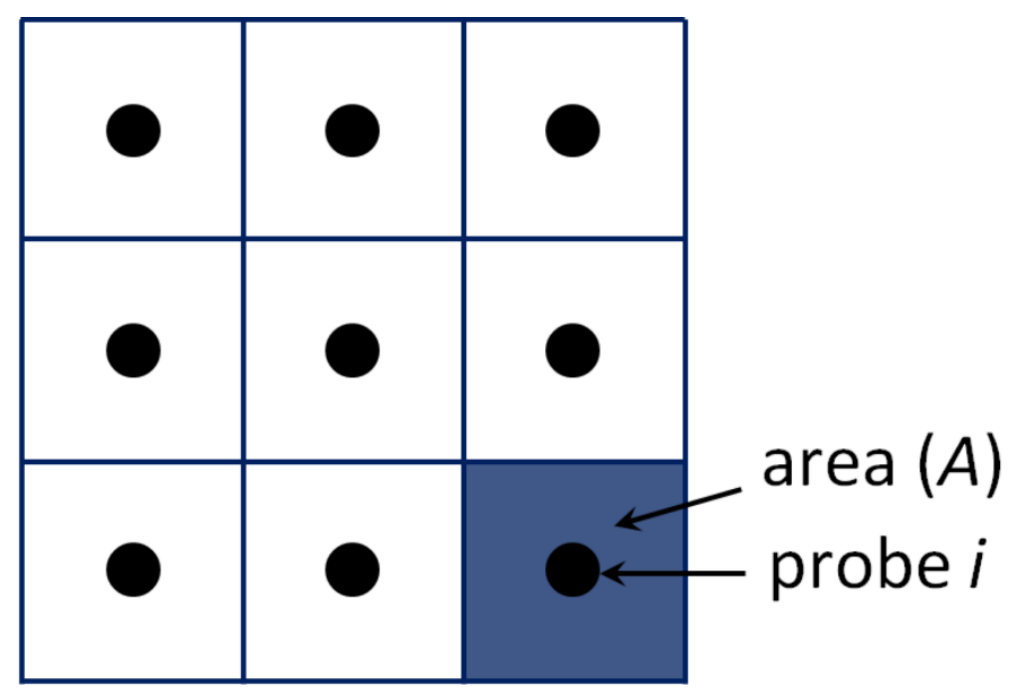

Fig. 2. Example arrangement of probes on the face of a structure. 


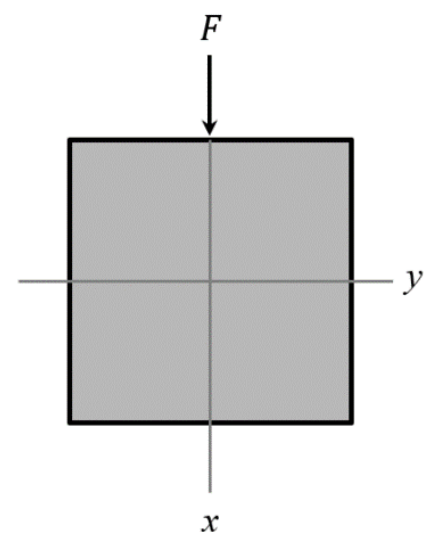

(a)

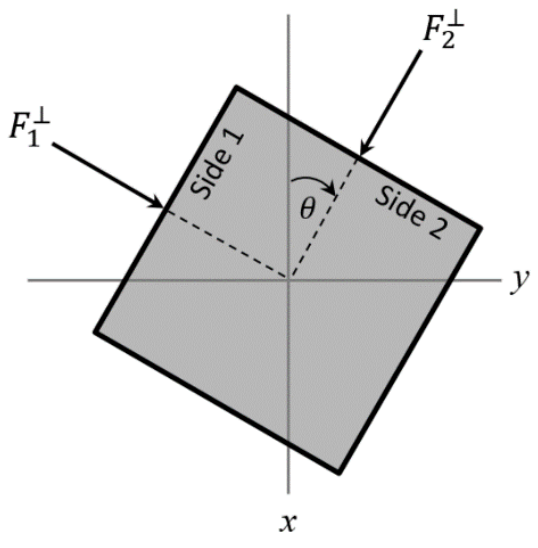

(b)

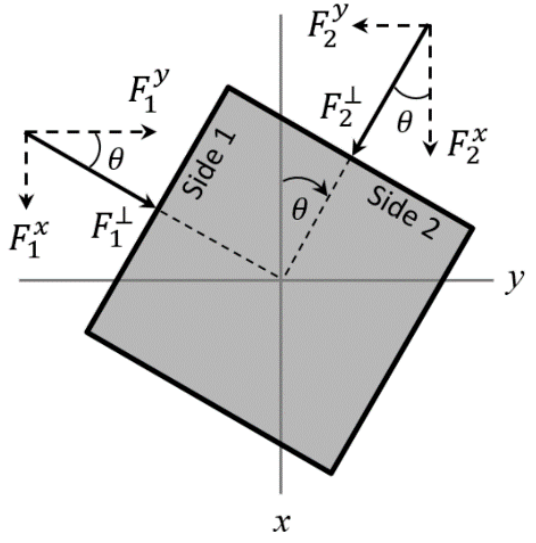

(c)

Fig. 3. Plan view of the structure and resolved force in $x$ and $y$-directions; (a) un-rotated structure, (b and c) rotated structures. 


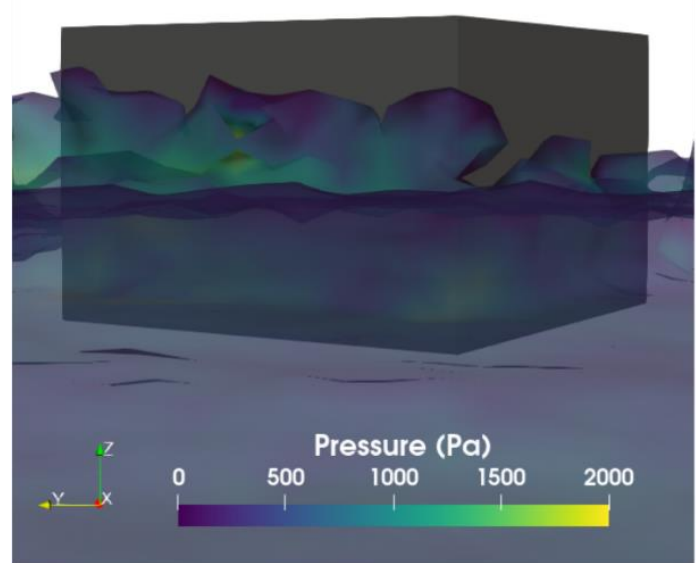

(a)

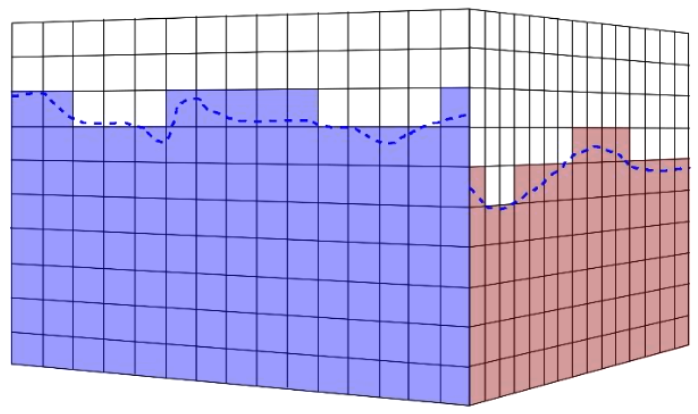

$\square$ un-loaded areas

$\square$ loaded areas on front-left side

loaded areas on front-right side

(c)

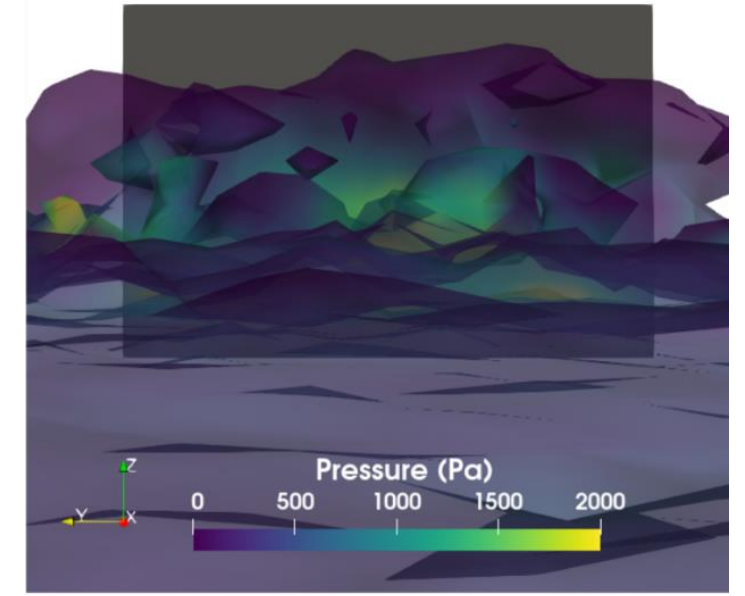

(b)

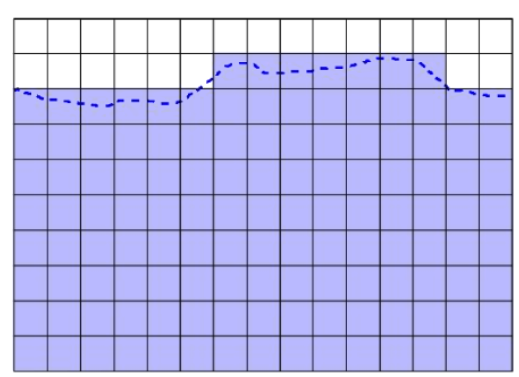

un-loaded areas

loaded areas on front side water level

(d)

Fig. 4. Numerical water elevations and loaded areas on vertical surfaces of (a and c) rotated structures and (b and d) un-rotated structure. 

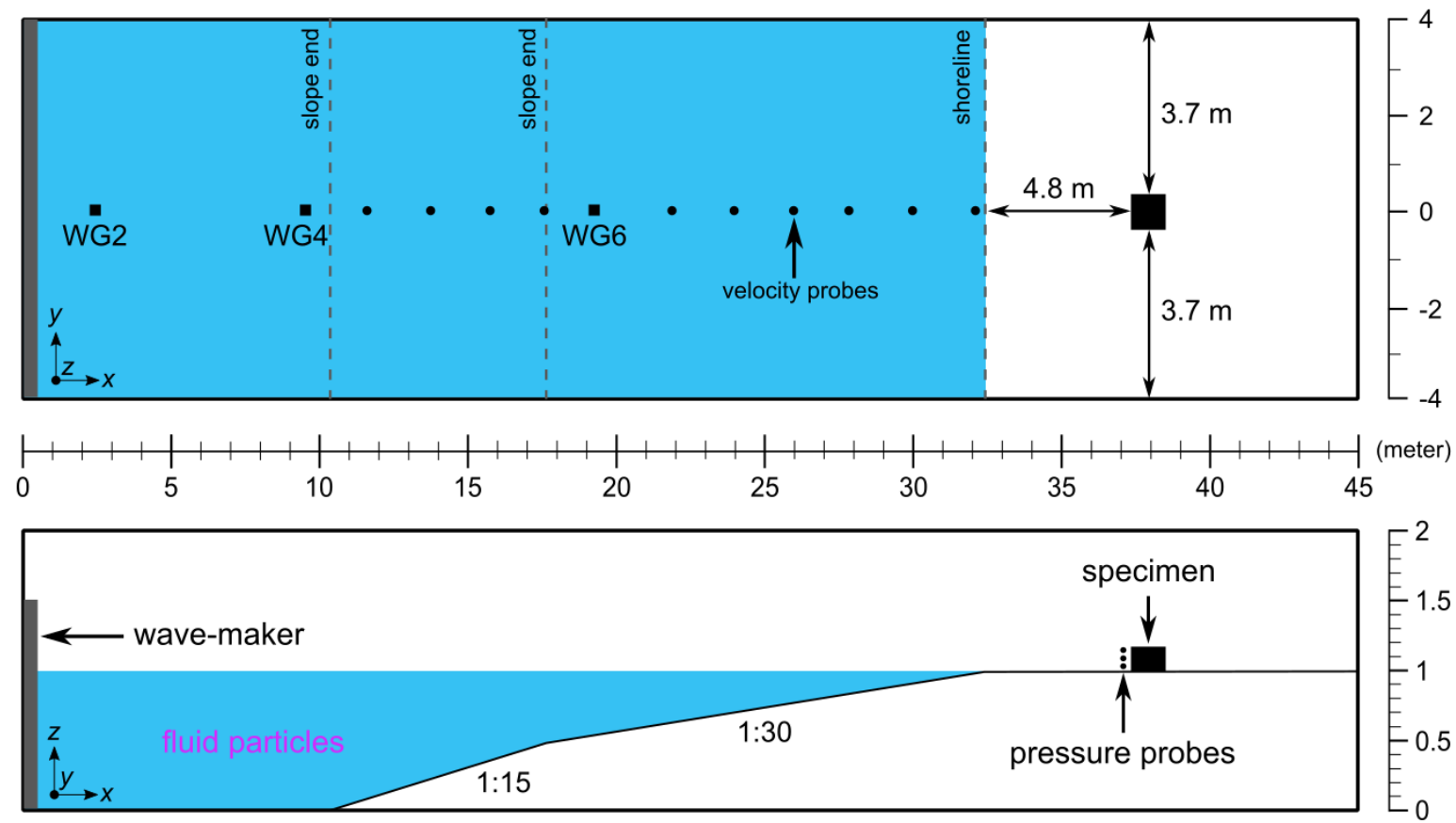

Fig. 5. Layout of the experimental water tank in Thomas et al. (2015), not to scale. 


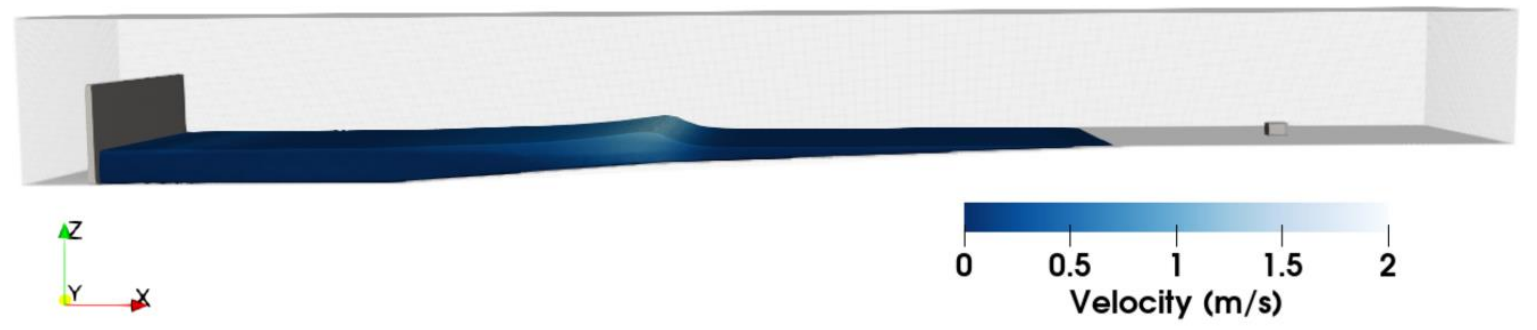

Fig. 6. Screenshot from the numerical model showing offshore wave propagation. 


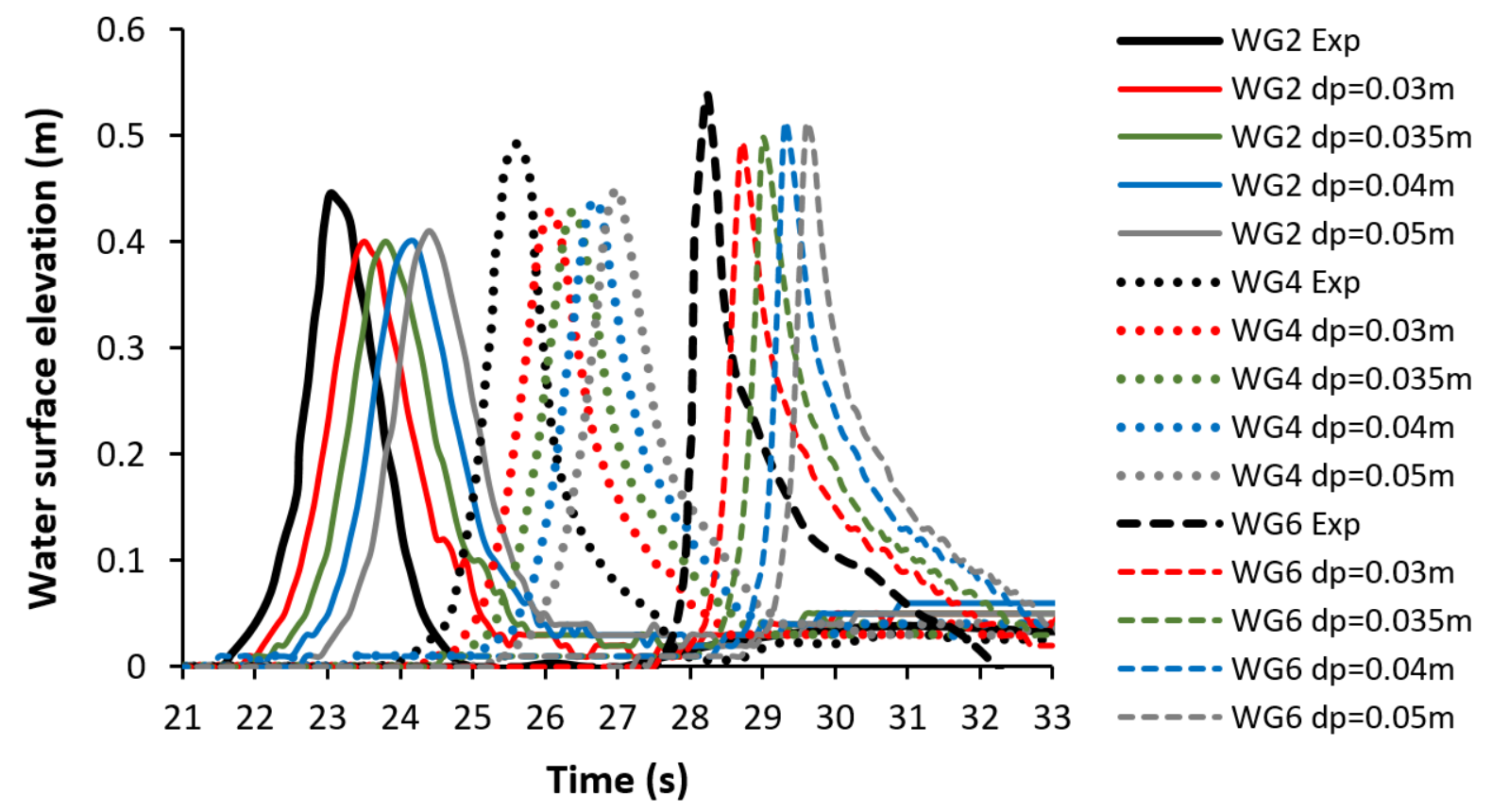

Fig. 7. Comparison of water surface elevations (time shifted by $0.3 \mathrm{~s}$ for clarity). 


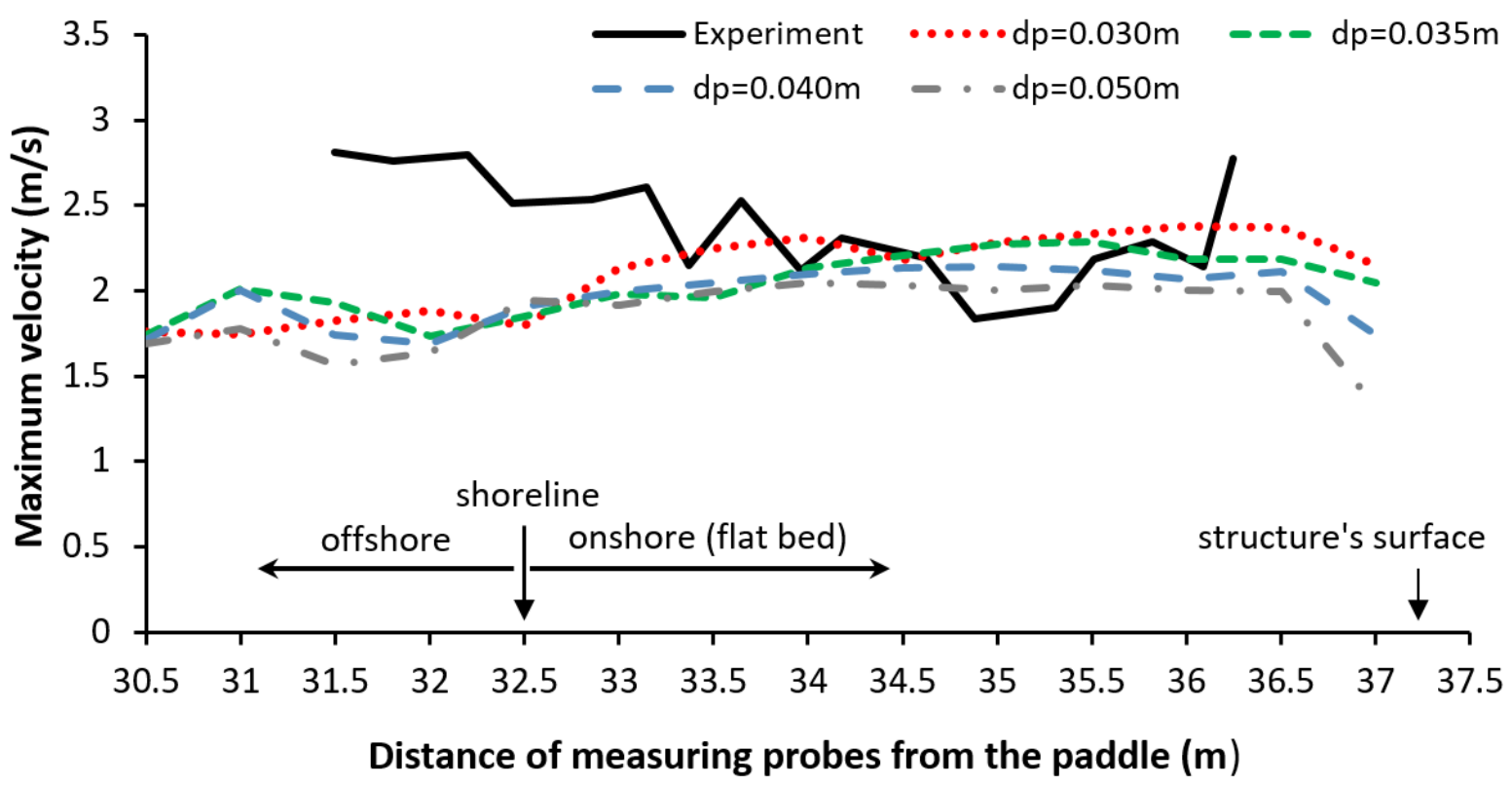

Fig. 8. Comparison of flow velocities. 

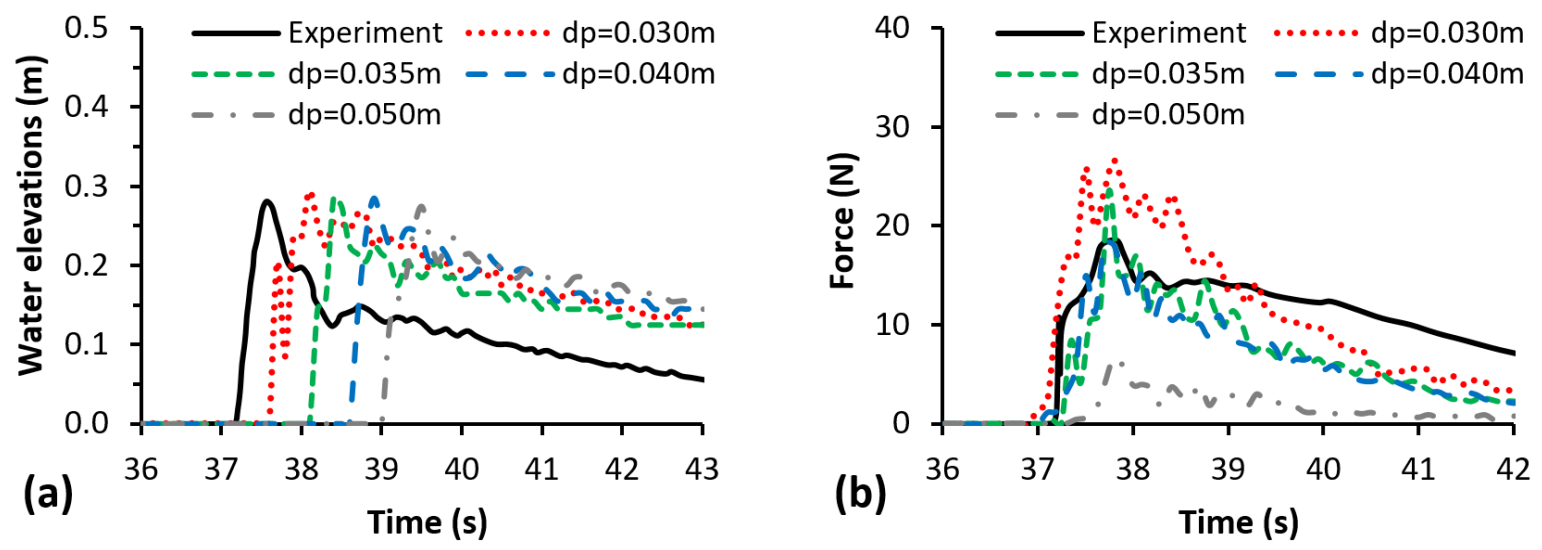

Fig. 9. Comparison of (a) water surface elevations of the bore at $37.25 \mathrm{~m}$ and (b) impact forces on structure. Numerical water surface elevations are shifted by $0.5 \mathrm{sec}$ for clarity. 


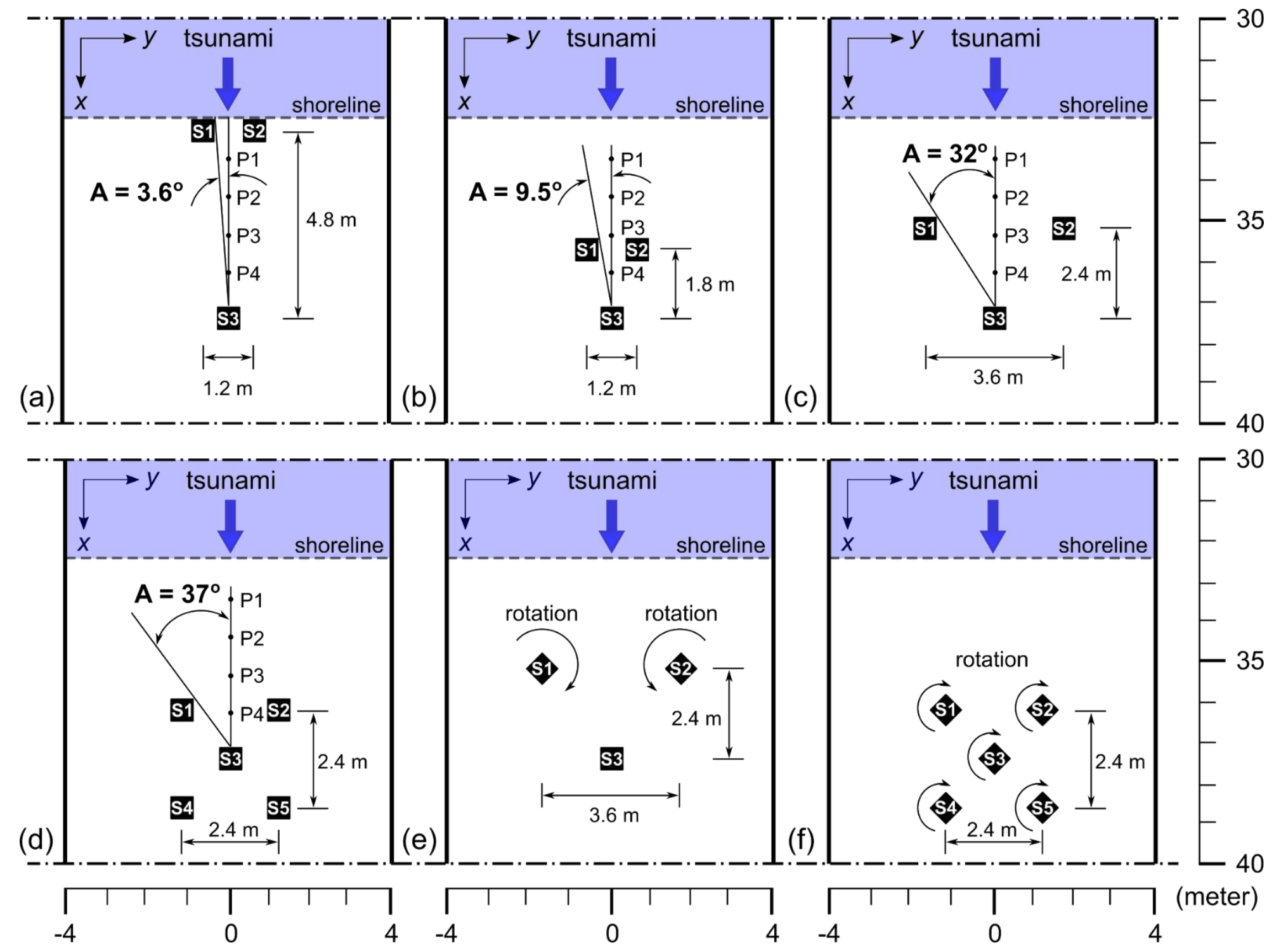

Fig. 10. Layout of multiple structure scenarios; (a) $\mathrm{A}=3.6^{\circ}$, (b) $\mathrm{A}=9.5^{\circ}$, (c) $\mathrm{A}=32^{\circ}$, (d) $\mathrm{A}=37^{\circ}$, (e) inward-rotation for front structures, (f) clockwise-rotation for all structures. 

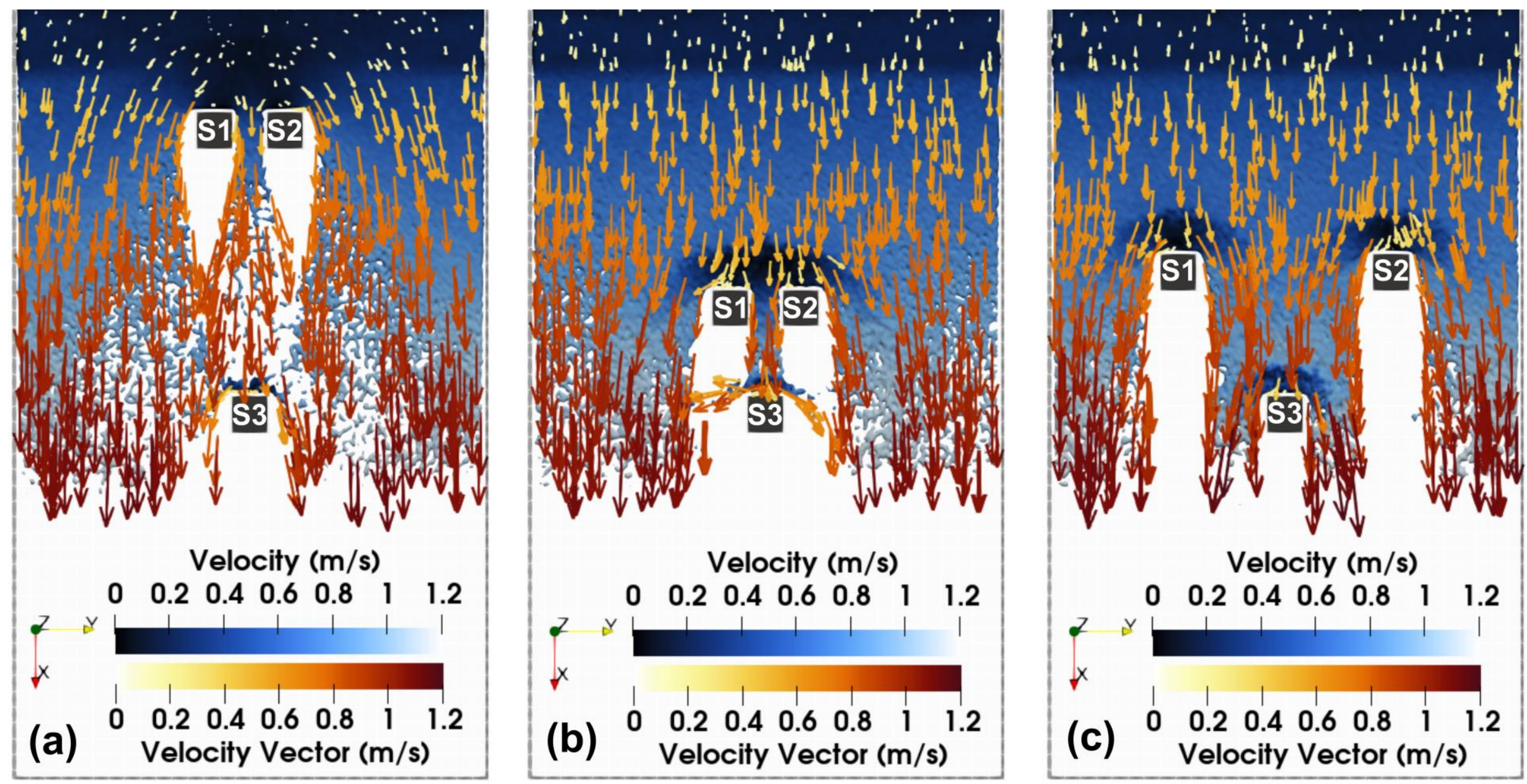

Fig. 11. SPH simulation of group of three structures without rotation for case with $\mathrm{A}=3.6^{\circ}(\mathrm{a}), \mathrm{A}=9.5^{\circ}(\mathrm{b})$ and $\mathrm{A}=32^{\circ}(\mathrm{c})$, at $t=19.3$ sec. 

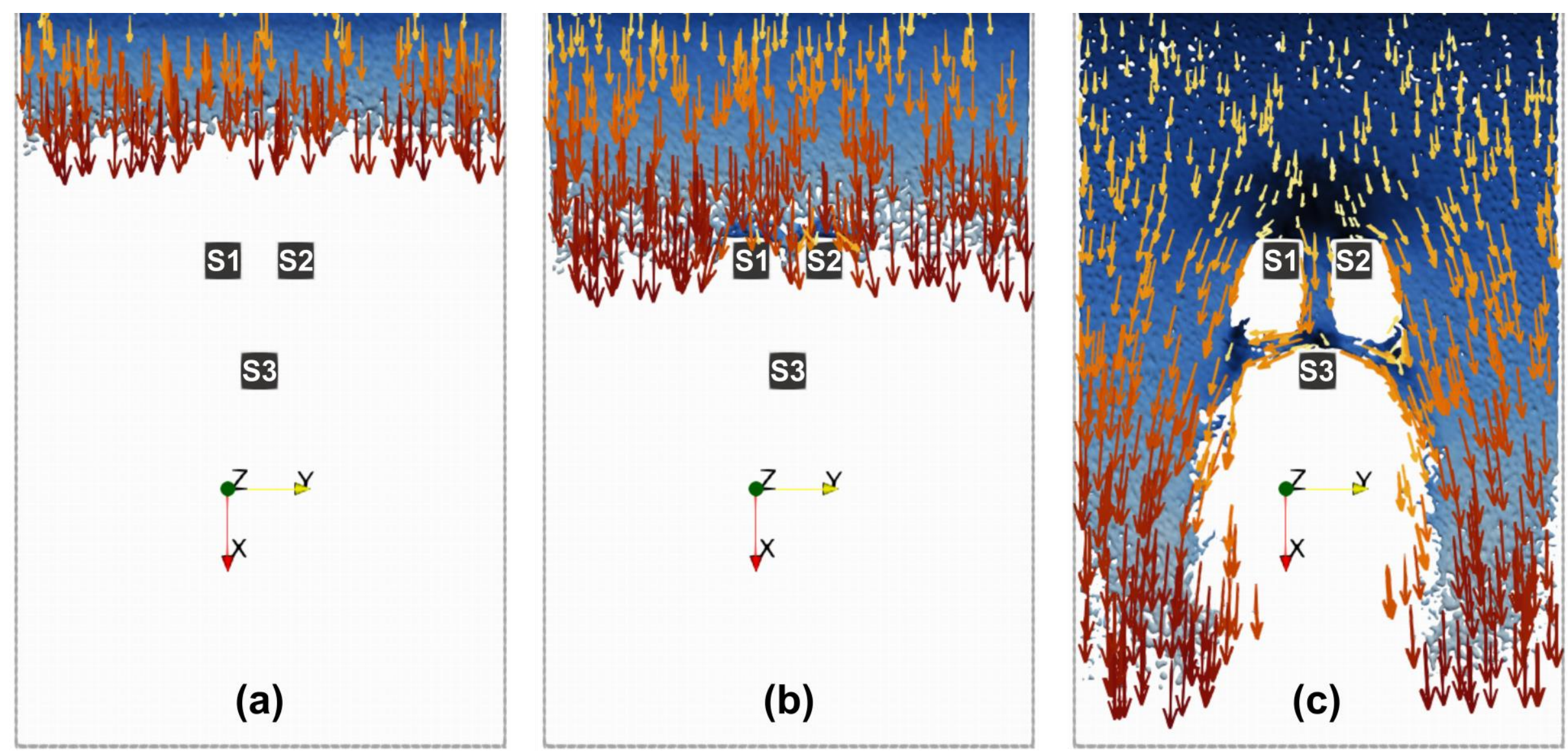

Fig. 12. Time sequence of bore-structure interaction for case with $\mathrm{A}=9.5^{\circ}$ at $t=17 \mathrm{~s}(\mathrm{a}), t=18 \mathrm{~s}(\mathrm{~b})$, and $t=21 \mathrm{~s}(\mathrm{c})$. 


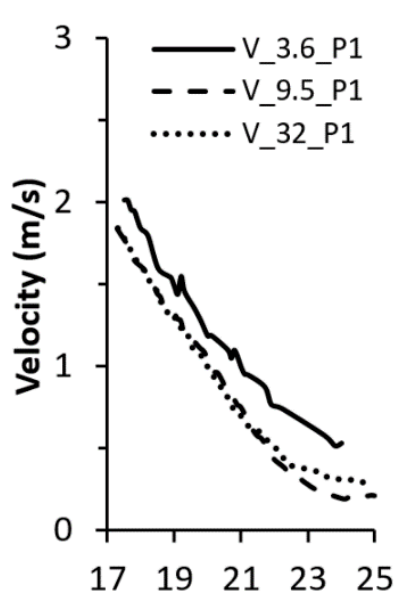

(a) Time (s)

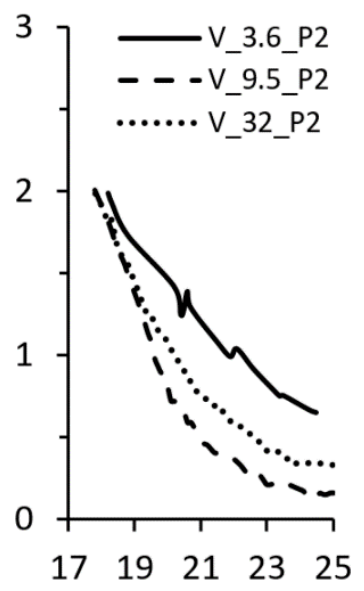

(b) Time (s)

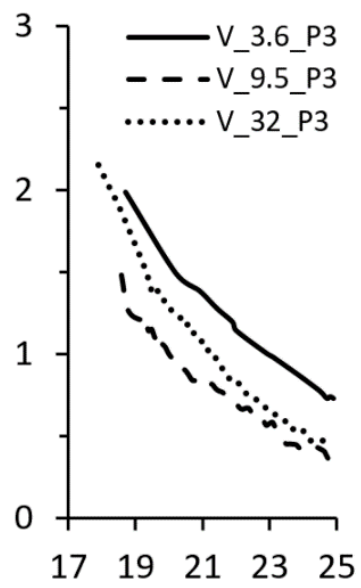

(c) Time (s)

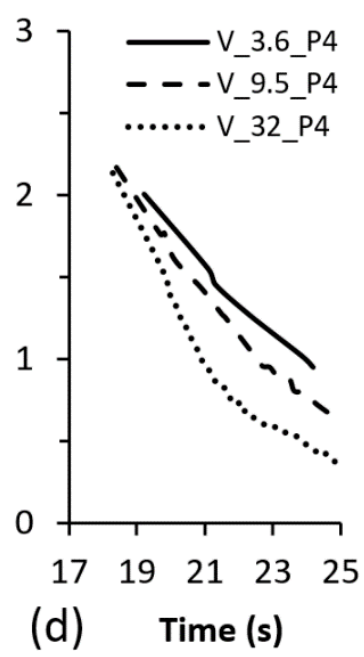

(d) Time (s)

Fig. 13. Velocities of tsunami flows at (a) P1, (b) P2, (c) P3 and (d) P4. The labels V_A_P correspond to the velocity measured for a specific case where $\mathrm{V}$ denotes velocity, $\mathrm{A}$ denotes the angle of separation, and $\mathrm{P}$ denotes one of probes $\mathrm{P} 1$ to $\mathrm{P} 4$. 


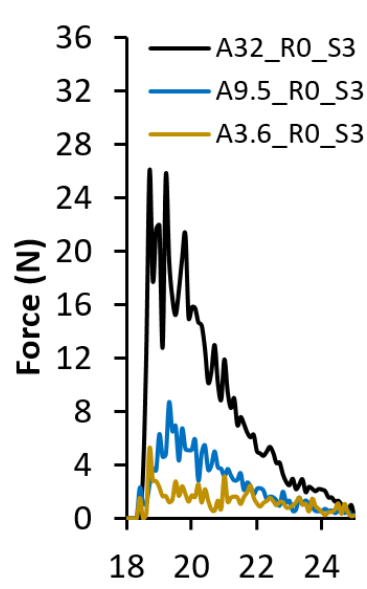

(a) Time (s)

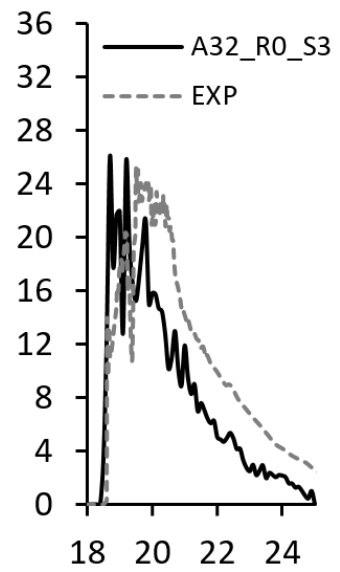

(b) Time (s)

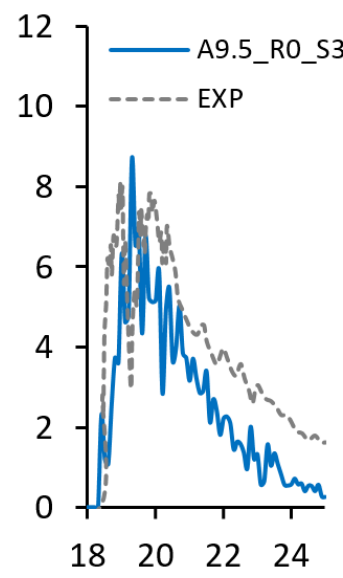

(c) Time (s)

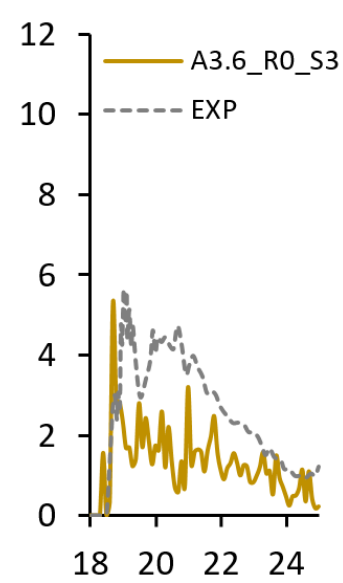

(d) Time (s)

Fig. 14. Total forces $\left(F_{\text {total }}^{x}\right)$ applied on $\mathrm{S} 3$ for multiple structure cases (a) and comparison with experimental result for case with $\mathrm{A}=32^{\circ}(\mathrm{b}), \mathrm{A}=9.5^{\circ}(\mathrm{c}), \mathrm{A}=3.6^{\circ}$ (d). 

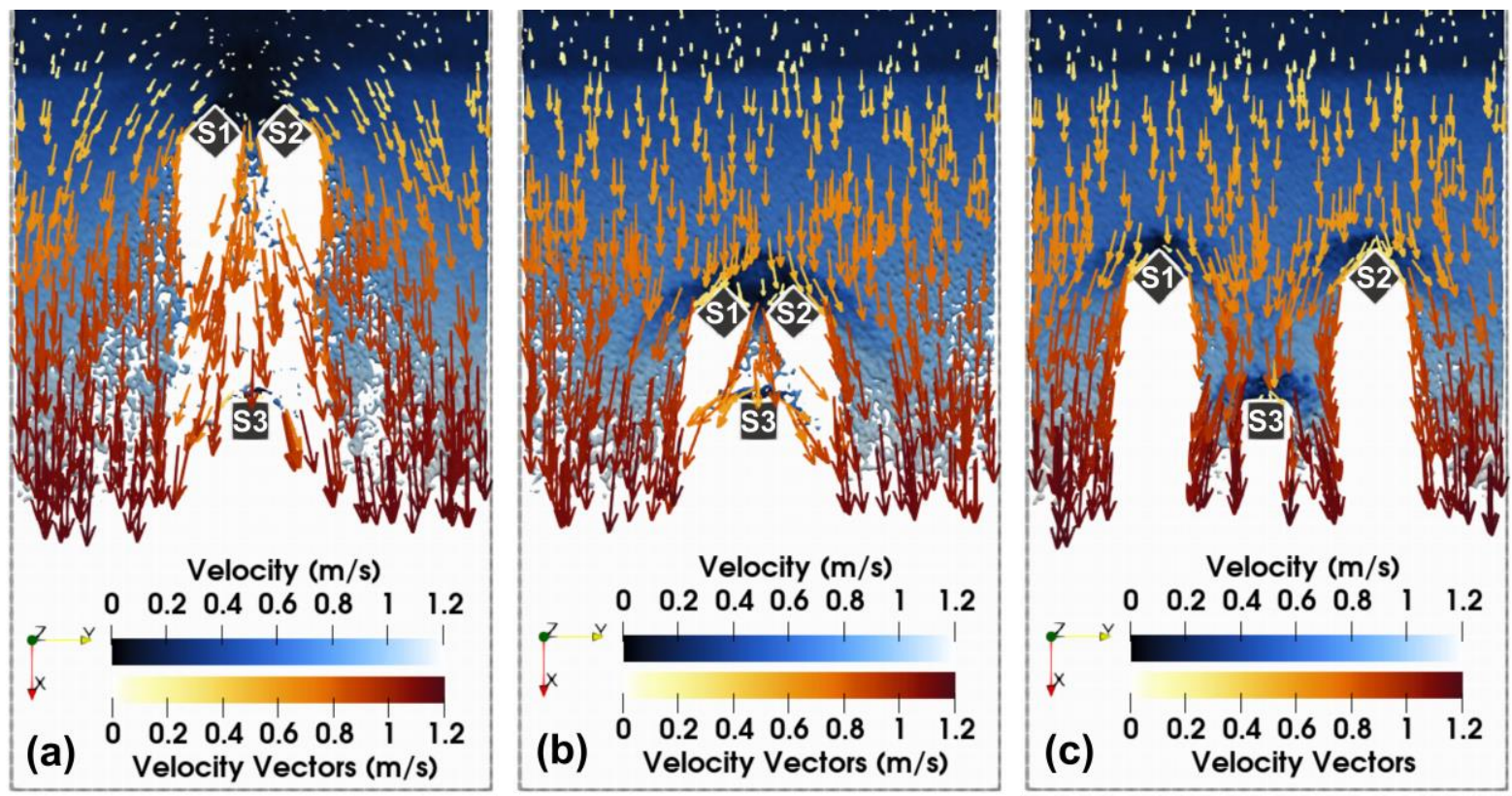

Fig. 15. SPH simulation of the group of 3 scenario for case with $A=3.6^{\circ}(a), A=9.5^{\circ}(b), A$ $=32^{\circ}(\mathrm{c})$, all with inward-rotation $\mathrm{R}=45^{\circ}$ for $\mathrm{S} 1$ and $\mathrm{S} 2$, at $t=19.3 \mathrm{sec}$. 

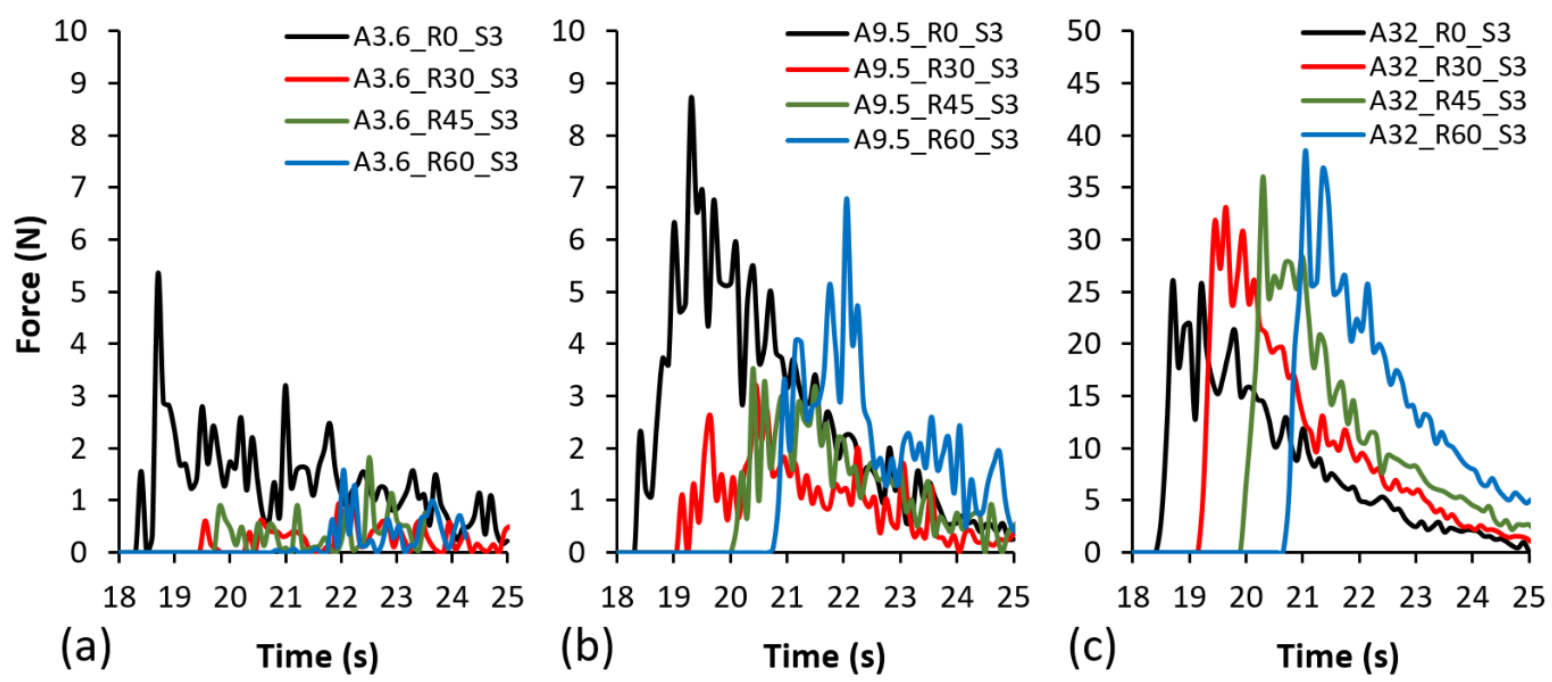

Fig. 16. Comparison of forces $\left(F_{\text {total }}^{x}\right)$ on $\mathrm{S} 3$ for case with $\mathrm{A}=3.6^{\circ}(\mathrm{a}), \mathrm{A}=9.5^{\circ}(\mathrm{b})$ and $\mathrm{A}=$ $32^{\circ}$ (c). 

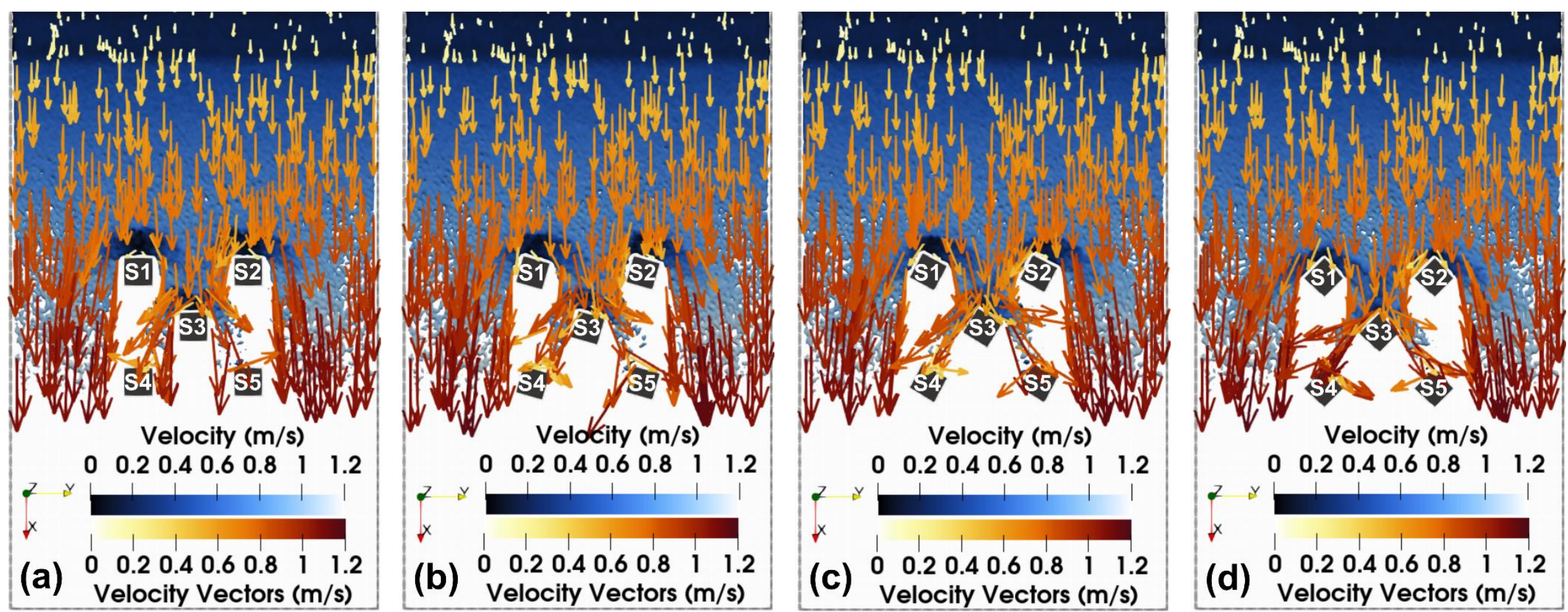

Fig. 17. SPH simulation of the group of 5 scenario $\left(\mathrm{A}=37^{\circ}\right.$ cases $)$ with $\mathrm{R}=0^{\circ}(\mathrm{a}), \mathrm{R}=15^{\circ}(\mathrm{b}), \mathrm{R}=30^{\circ}(\mathrm{c}), \mathrm{R}=45^{\circ}(\mathrm{d})$, at $t=19.3$ sec 

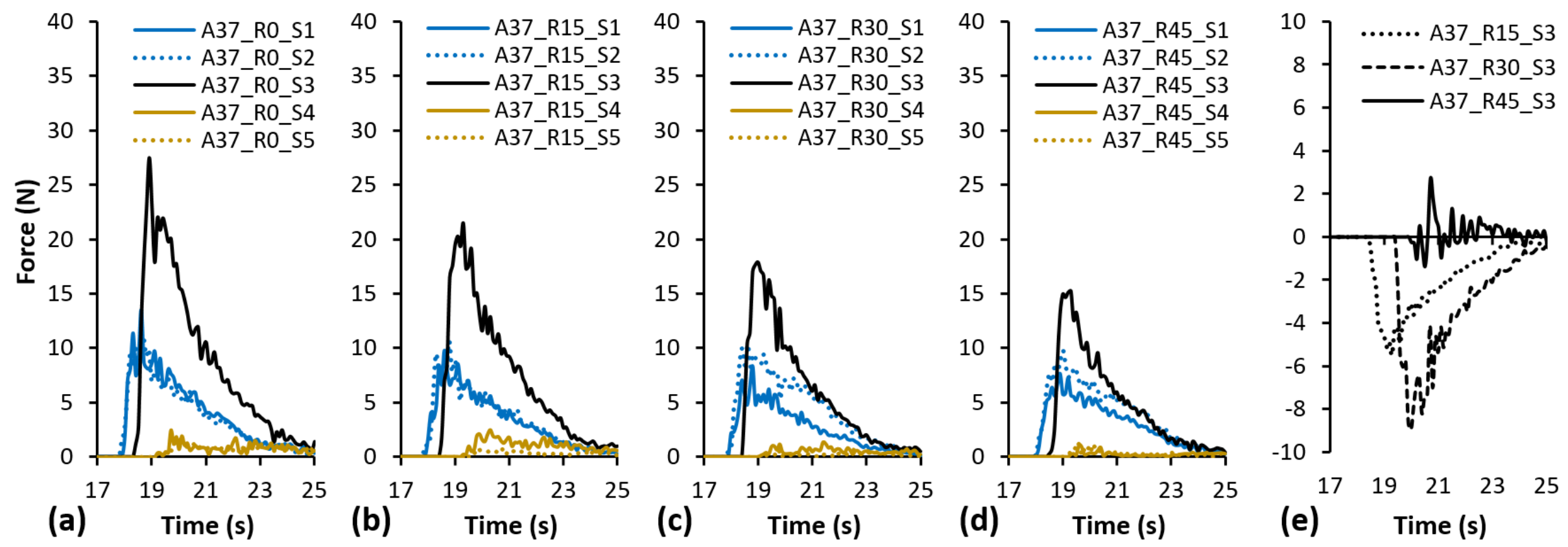

Fig. 18. (a-d) Total forces $\left(F_{\text {total }}^{x}\right)$ on all structures for the group of 5 scenario $\left(\mathrm{A}=37^{\circ}\right.$ cases $)$, (e) Total forces $\left(F_{\text {total }}^{y}\right)$ 

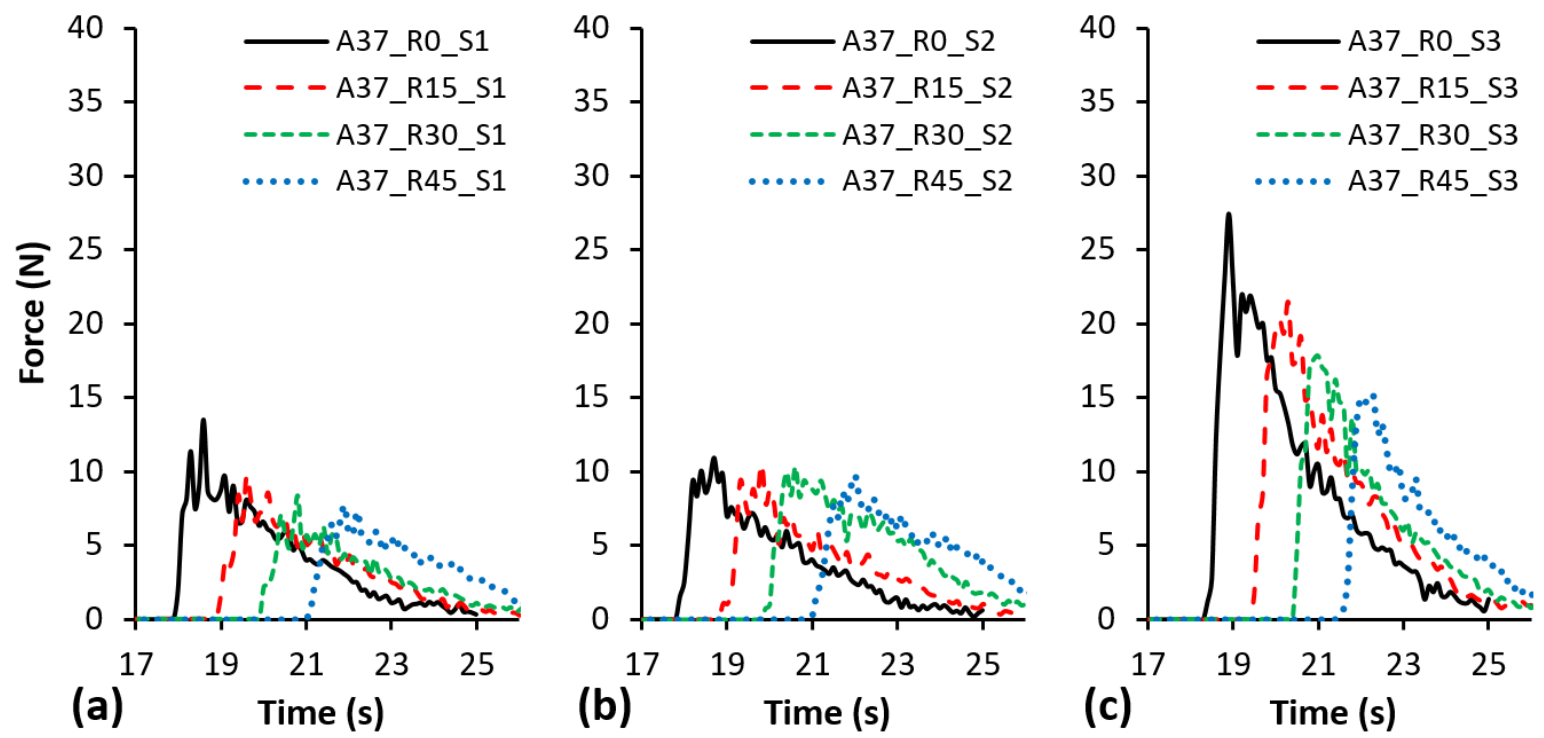

Fig. 19. Comparison of total forces $\left(F_{\text {total }}^{x}\right)$ on $\mathrm{S} 1, \mathrm{~S} 2$ and $\mathrm{S} 3$ for the group of 5 scenario $\left(\mathrm{A}=37^{\circ}\right.$ cases $)$ 


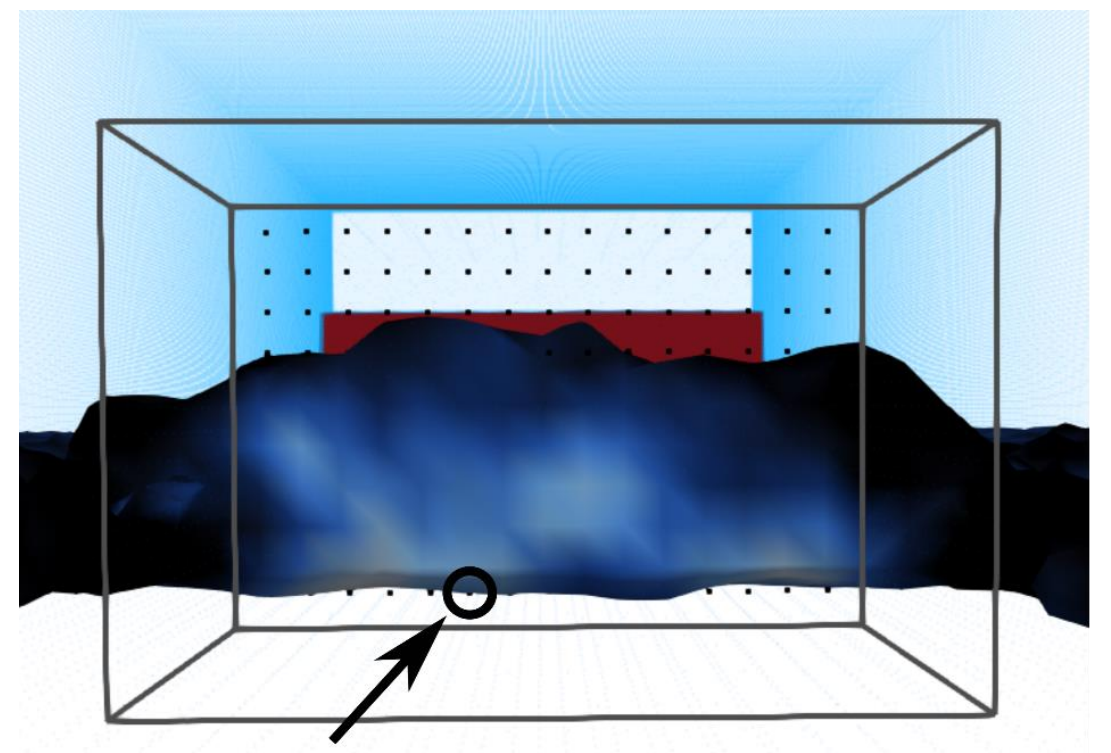

Pressure (Pa)

Q $0 \quad 2004006008001000120014001600$

(a)

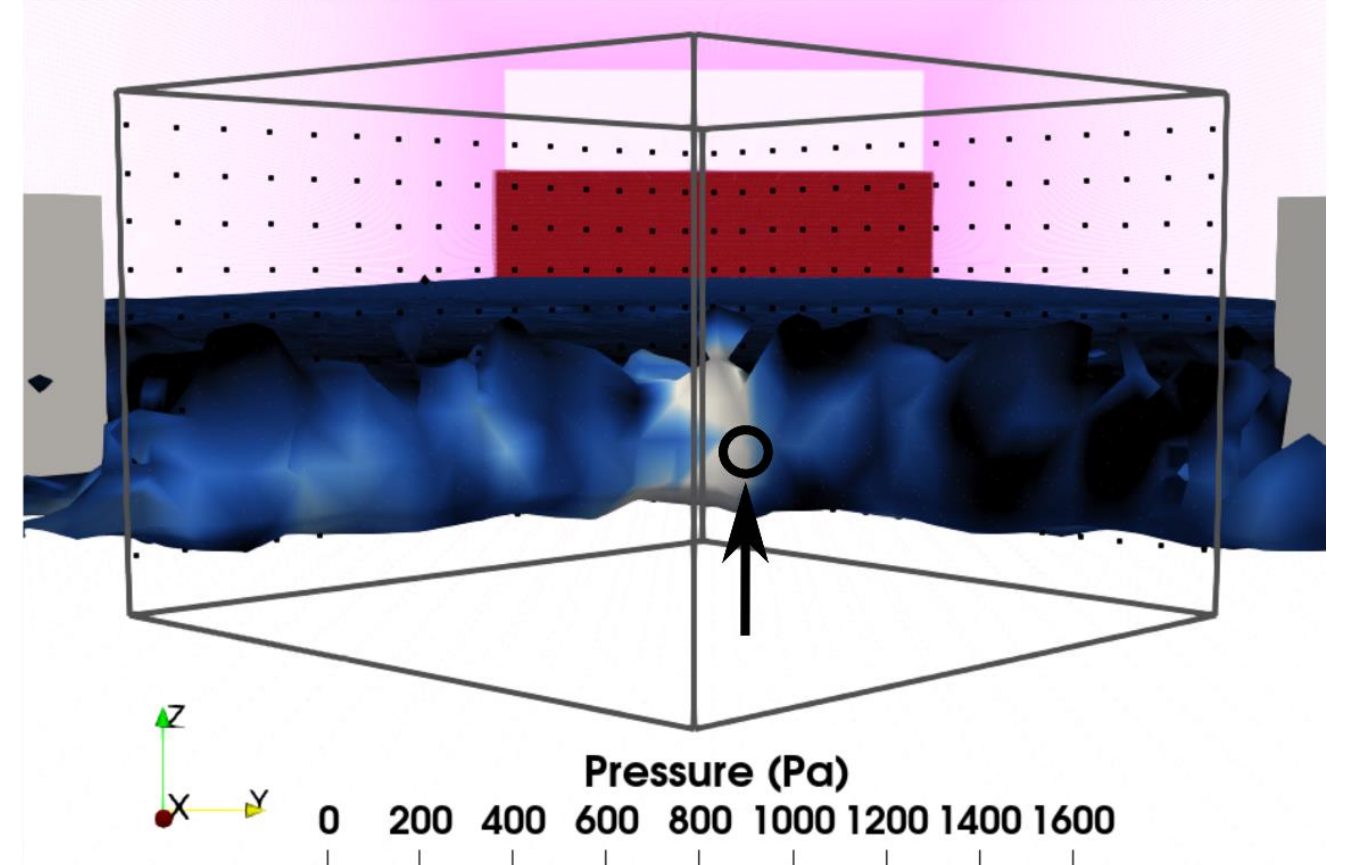

(b)

Fig. 20. Peak impact pressure position on main structure S3; (a) R0, (b) R45. 